\title{
A 50-year hydro-climatological assessment of climatic modes over the world's major mountain ranges
}

\begin{abstract}
Ahmed M. El Kenawy ${ }^{1}$, Hossam Ismael ${ }^{2}$
Abstract

The observed climate response and variability that has occurred over the five decades since 1960 of 13 largest global mountain regimes (i.e. the European Alps, Anatolia, Andes, Applach, Atlas, Australian, Brooks, Ethiopian, Himalaya, Kolyma, Rocky, Pyrenees, and Scandinavian) to climate variability. This study covers the period 1960-2013, with a particular emphasis on changes in air temperature and precipitation conditions and their joint modes. Results demonstrate that mountains of high-latitudes in the Northern Hemisphere (e.g. Brooks, Kolyma, and Scandenavia) experienced the largest trends of air temperature $\left(0.24-0.45^{\circ} \mathrm{C} / \mathrm{decade}\right)$. In contrast, changes in air temperature in mountains of the Southern Hemisphere (e.g. Australian and most of the Andes) and the subtropics (e.g. Ethiopian mountains) were generally weaker than those of the mid- and highlatitudes of the Northern Hemisphere. Notably, temperature changes were stronger in low- and mid-elevation regions (e.g. Alps, Pyrenees, Brooks, and Kolyma), compared to the most elevated regions (e.g. Himalaya and Andes). Precipitation exhibited heterogeneous changes, with pronounced decrease over the Alps, Pyrenean and Ethiopian mountains and conversely significant increase across the northern high-latitudes mountains (e.g. Scandinavian and Applach). Factor analysis was also used to identify common patterns of interannual variability among all mountain systems. Results suggest three components with distinctive temporal evolution that explain together $72.72 \%$ of air temperature variability. In contrast, the temporal evolution of annual precipitation was more heterogeneous, with six components accounting for $68.59 \%$ of precipitation variability. This study also accounted for the possible joint changes in air temperature and precipitation by assessing changes in four different climatic modes (i.e. warm and wet [WW], warm and dry [WD], cold and wet [CW] and cold and dry $[C D])$, Changes in air temperature, precipitation and their joint modes were further linked to a range of the key circulation patterns over the Northern and Southern Hemispheres, e.g. the Atlantic Meridional Mode [AMO], the Atlantic Multidecadal Oscillation [AMO], the Arctic Oscillation [AO], the Multivariate ENSO Index [MEI], and the North Atlantic Oscillation [NAO]. Results of this work can advances our knowledge of the role of climate variability and change in mountain environments, giving insights into their possible ramifications for different environmental and socioeconomic sectors (e.g. freshwater supply, hydropower generation, biodiversity conservation, ...etc). [Bul. Soc. Géog. d'Égypte, 2019, 92: 1-39]
\end{abstract}

Keywords: Precipitation; Air temperature; Climate modes; Topographic gradients; Circulation patterns; Mountains.

\section{Introduction}

Assessing the response of mountainous regions to climate change and variability is of utmost importance from various hydrometeorological, ecological and environmental perspectives. Climatologically, these regions are characterized by their high interannual and intrannual variability, as a consequence of topographical gradient, vertical motion of air advection, besides the varying albedo associated with different land cover and slope angel (Pepin and Lundquist, 2008; Siler and Roe, 2014). Hydrologically, orographic precipitation and accumulated snow pack are known to serve as a key source of fresh water for many countries worldwide (Lopez-Moreno et al., 2013). According to Barnett et al. (2005), snowtopped mountains are the major source of several perennial and intermittent rivers downstream, contributing to more than $25 \%$ of the global gross domestic water. However, in the era of accelerated warming, particular attention is required since hydrological

\footnotetext{
${ }^{1}$ Instituto Pirenaico de Ecología, Campus de Aula Dei, Avda. Montañana, 50059, Zaragoza, Spain. Department of Geography, Mansoura University, Mansoura, Egypt. E-mail: (kenawy@mans.edu.eg

${ }^{2}$ Department of geography and GIS, New Valley University, Egypt._hosam.ismael@artnv.au.edu.eg
} 
characteristics in these regions are mainly driven by the complex interactions between climate and orography. According to the IPCC (2013), the annual runoff and water availability are likely to decrease globally by $10-30 \%$ in the future, in response to the enhanced greenhouse gas emissions. Furthermore, mountains are key sources of hydropower energy, minerals, forest and agricultural products and present attractive areas for recreation as well (UN, 1992). Mountain regions are also more vulnerable to several human activities, which aggravate grassland degradation, desertification, landslides, soil erosion and ecological deterioration (He et al., 2017). All these physical and human stressors combine together to make mountain environments amongst the most vulnerable regions to global warming (Beniston, 2003; Gobiet et al., 2014; Shen et al., 2015). As such, there is strong evidence that climate change can add considerable challenges to different sectors in mountain regions, including biodiversity conservation, sustainable management of natural resources, agriculture, water supply, power generation and tourism (Morrison and Pickering, 2013; Gaudard et al., 2014). For example, from biodiversity perspective, mountainous regions can secure 'safe' environments to help protect species from human threats and accordingly enrich wildlife (Rands et al., 2010). However, numerous studies indicate that different species have shifted their spatial distributions in mountainous terrain, as a consequence of recent climate change (e.g. Gottfried et al., 2012; Alagador et al., 2014).

Albeit with their coverage of more than $25 \%$ of continental surfaces (Kapos et al., 2000), characterization of climate variability in complex terrain is not well-documented from a global perspective. This is mainly because of the uneven distribution of climatic information over space and time, particularly at more elevated sites. Even with data availability, there is often a degree of uncertainty in climate signals due to accessibility difficulties (e.g. strong winds, frequent snowfall events,...etc), which can hinder routine maintenance at meteorological observatories (Shamir et al., 2016). Also, mountain regions exhibit strong climate gradients, which are poorly represented by the available limited spatial and temporal coverage of meteorological data, adding further uncertainty to observed climate signals in these data scarce regions (Remesan and Holman, 2015). Also, mountain regions are characterized by complex interactions between a wide range of processes that drive climate variability (e.g. free atmospheric flow, larger-scale atmospheric circulation, snow and ice feedbacks, urbanization, topography, land cover, surface exposure,...etc) (Siler and Roe 2014). As a consequence of these convoluted interactions, the hydrological feedbacks to climate change can vary considerably even from one catchment to another, which requires highly dense spatial hydroclimatic datasets to precisely characterize these feedbacks.

Recalling all these challenges, little is known about the response of large mountainous regions to climate change signals and whether this response is consistent among these systems, particularly with their different topographical gradients and regional and large-scale climate drivers. Overall, most of the available studies are not spatially distributed, as they either focused on an individual mountain system or a particular plot of it. Specifically, previous research has been narrowly focused on characterizing climate variability across individual mountain regions, notably the European Alps (e.g. Beniston et al., 1997, 2003, 2009; Giorgi et al., 1997; Gaudard et al., 2014; Gobiet et al., 2014), the European midelevation mountain ranges such as the Pyrenees (e.g. López-Moreno et al., 2011b; El Kenawy et al., 2012) and the Carpathian mountains (e.g. Spinoni et al. 2015), the Tibetan Plateau and surrounding mountains (e.g. Chen et al., 2003; Maussion et al., 2014; Pankaj et al., 2015), and the North American mountains (e.g. Fyfe and Flato, 1999; Hamlet et al., 2005; Trenberth et al., 2007; Bonfils et al., 2008). For example, Pepin and Lundquist (2008) employed homogeneity-adjusted climatic records from 1084 high-elevation stations, provided by the Global Historical Climate Network (GHCNv2) and Climate Research Unit (CRUv2), to characterize temperature trends and assess their dependency with different topographic 
features (e.g. elevation, aspect, and exposure). Over a range of mountain systems in the Mediterranean region, López-Moreno et al. (2011a) explored the impacts of the North Atlantic Oscillation (NAO) on the temporal evolution of winter surface air temperature and precipitation and their future projections using an ensemble of Global Circulation Models (GCMs) under a moderate (A1B) greenhouse gas emissions scenario. Also, Nogués-Bravo et al. (2007) assessed projected changes in air temperature across a range of mountain systems worldwide, indicating that they are likely to witness an increase by the end of the $21^{\text {st }}$ century on the order of $2.8^{\circ} \mathrm{C}$ in temperate areas and $5.3{ }^{\circ} \mathrm{C}$ in northern latitudes.

A quick inspection of these studies reveals that there are no attempts to make a comparison among the global mountain systems to explore their possible different responses to recent climate change, particularly in the sense of the concurrent changes of key climate variables (e.g. air temperature and precipitation). There is compelling evidence that the combined effects of temperature and precipitation changes could impact positively or negatively important components of the hydrological cycle in mountainous environments (e.g. runoff availability, snowpacks melting, soil moisture conditions, ...etc), besides changes in other ecosystem functions (e.g. vegetation growth and distribution, species structure). According to Trenberth and Shea (2005), temperature rise may be modulated by an increase in precipitation, as wet conditions can favor for less sunshine and correspondingly more evaporative demand. As such, assessing the covariability between surface air temperature and precipitation and its large-scale driving forces in the main global mountain systems is important to demonstrate how changes in precipitation are accompanied by surface warming, and consequently how this determines the response of these ecosystems to recent climate change.

The objectives of this study are threefold. It aims to (i) assess changes in surface air temperature and precipitation over 13 global main mountain system over the period 19602013 using CRUTS-V3.22 dataset, (ii) explore covariability between temperature and precipitation modes over these mountain regions using a joint-percentile approach, and (iii) define the most significant circulation patterns contributing to this covariability. This global assessment is desired to improve current understanding of the extent to which complex terrain regions respond to changing climate, to characterize their regional variations and to understand their different environmental and socioeconomic implications.

\section{Description of the main mountain systems}

Our study focused on 13 main mountain systems in the world, including the European Alps, Anatolia, Andes, Applach, Atlas, Australian, Brooks, Ethiopian, Himalaya, Kolyma, Pyrenees, Rocky and Scandinavian systems (Figure 1). The boundaries of each mountainous region was defined from a 30-meter SRTM Digital Elevation Model (DEM), based on topographic parameters, such as altitude, mean slope and topographical gradients with neighbouring grids (http://www.dgadv.com/srtm30/). The selected mountain systems account together for approximately $7 \%$ of the total land surface, with the Himalaya, Rocky and Andes being mega systems expanding over approximately $1.95,1.55$ and $0.81 \%$ of the total land surface area, respectively. In contrast, the Pyrenees, Alps, Atlas and the Ethiopian mountains represent more "localized" systems, accounting only for $0.02,0.15,0.20$ and 0.21 of the total land surface. As illustrated in Figure 2, the mountain systems are distributed over the Northern and Southern Hemispheres and almost cover the whole latitudes, albeit with particular distribution over the mid-latitudes $\left(30-60^{\circ}\right)$ of the Northern Hemisphere (e.g. Alps, Anatolia, Applach, Atlas, Himalaya, Pyrenees and Rocky). Apart from the Andes and Himalaya, other mountain systems have altitudes generally lower than $2000 \mathrm{~m}$ (Figure 2). The selected mountain systems show remarkable differences in their orientation, as some systems have a general meridional orientation (e.g. Andes, Rocky, and Australian 
mountains), whereas other systems exhibit a zonal extension (e.g. Alps, Anatolia, Brooks, Kolyma, Himalaya, and Atlas). Climatologically, the selected mountain systems are characterized by their high interannual and intrannual variability of climate. The selected mountain systems show considerable differences with respect of the seasonal cycle of surface air temperature and total precipitation (Figure 2). The Brooks and Kolyma mountains belong to polar climates, with air temperature notably below zero for most of the year. Apart from the mountain systems in the Southern Hemisphere (i.e. Australian and Andes mountains), other systems show a consistent seasonal cycle, with higher temperatures from May to September. Notably, while some mountain systems show low month-to-month temperature variability in the tropical (i.e. Ethiopian mountains) and sub-tropical mountains (i.e. Australian mountains), other systems in the mid and high latitudes show higher inter-month variance. For precipitation, the mountain systems show more temporal variations compared to air temperature, with some systems showing their peaks over summer months (e.g. the Ethiopian, Himalaya, Kolyma, Brooks and Applach), while others receive the majority of its precipitation during winter (e.g. Scandenavia) and springtime (e.g. Anatolia and Pyrenees). Few systems exhibit doubly precipitation peaks (e.g. the Atlas), whereas other systems have no peaks the year-round (e.g. the Andes). Overall, these complex spatiotemporal patterns indicate that climate variability is largely impacted by a wide range of large-scale physical processes and configurations (e.g. tropical and subtropical configurations, westerlies, polar fronts, maritime-continental influences,...etc), as well as regional and local drivers (e.g. topographical gradient, land cover,...etc).

\section{Data and methodology}

\subsection{Dataset description}

We assessed changes in annual surface air temperature $\left({ }^{\circ} \mathrm{C}\right)$ and total annual precipitation (mm) using data from CRU TS (v.3.22). This is a monthly global climatic dataset developed and maintained by the Climatic Research Unit (CRU) at the University of East Anglia (UK) via https://crudata.uea.ac.uk/cru/data/hrg/cru_ts_3.22/cruts.1406251334.v3.22/. The monthly gridded fields data are available at a $0.5^{\circ}$ grid resolution for land areas for the period from 1901 to 2013 (Harris et al., 2014). The gridded fields of CRU TS 3.22 are based on monthly observational data calculated from daily/sub-daily observational data provided by National Meteorological Services and external agents. CRU TS 3.22 provides actual climatic records rather than anomalies through combining monthly anomalies with a mean climatology that accounts for the possible influence of changes in elevation. For surface air temperature, CRU TS 3.22 employed data from 5,159 meteorological land stations worldwide, merged with the Sea Surface Temperature (SST) data from the Hadley Centre, compared to more than 11,500 of rain gauges (Harris et al., 2014). More details about the development of CRU TS 3.22 are outlined in Harris et al. (2014). Over the past few years, CRUTS-v3.22 has been evident as a well-suited dataset for many hydrometeorological applications in different regions worldwide, including trend assessment (e.g. El Kenawy et al., 2016; Hoffman et al., 2018), climate models validation (e.g. Lopez-Moreno et al., 2011a), besides other environmental applications (e.g. Ray et al., 2015).

Herein, it is noteworthy to indicate that while CRU TS 3.22 relied on substantially lower density of rain gauges than the most popular Global Precipitation Climatology Centre dataset (GPCC), it is more advantageous in the sense that it provides continuous long-term data for numerous climatic variables at consistent spatial interval. This aspect is important, as it allows for assessing directly the covariability between surface air temperature and precipitation, which is of a particular emphasis in this work. Our analysis was restricted to the time period 1960-2013 to limit the possible impacts of the irregular distribution of meteorological stations over both space and time during the earlier decades (i.e. before 1960) of the $20^{\text {th }}$ century. In this work, we employed surface air temperature and total precipitation 
aggregated at the annual scale for each grid interval corresponding to the 13 mountain systems. While surface air temperature is the most important component of mountain climate, due its important role in the surface-atmosphere energy exchange processes scale (Vinnikov et al., 1990; Barry, 1992), precipitation is a key component of its hydrological cycle, being one of the most fundamental parameters in land surface processes (e.g. runoff generation, groundwater recharge, soil moisture, soil degradation) (Burke et al., 2009; Smith and Vivenkananda, 2012).

\section{Methodology}

\subsubsection{Trend detection}

To define the amount of change in annual surface air temperature and annual total precipitation, we applied the ordinary linear least squares (OLS) regression method. As parametric tests assume a Gaussian distribution as well as spatial and temporal independence of data, we assessed the statistical significance of the detected changes by means of the modified Mann-Kendall statistic at the 95\% confidence interval $(\mathrm{p}<0.05)$ (Hamed and Rao, 1998). Similar to the standard Mann-Kendall statistic, this test is non-parametric, with no prior assumption of data distribution. More advantageously, it limits the possible influence of data serial autocorrelation on trend detection. This test determines the sign of the trend, indicating a stronger signal as the deviation from zero is greater.

In an attempt to characterize the association between changes in surface air temperature and total precipitation for each mountain system, we employed the contingency tables that provide insights into whether trends at gridpoint scale are consistent. To construct the contingency tables, we used air temperature and precipitation as the random variable, while the categories of the trends were the characteristics of the random variable. Specifically, for each mountain system, the trends of climatic variables (i.e. air temperature vs. precipitation) were grouped into four categories according to their sign (i.e. positive vs. negative) as well as their statistical significance $(\mathrm{p}<0.05)$ (i.e. significant vs. insignificant). According to this procedure, the trends at each gridpoint can be classified as: positive and significant [+], negative and significant [-], positive and insignificant $[+\mathrm{N}]$, or negative and insignificant [$\mathrm{N}]$. Pivot tables were constructed to represent the cross-categorized frequency data in a matrix format following the results of the trend analysis.

\section{Covariability of air temperature and precipitation}

In this study, we also explored the co-variability of surface air temperature and precipitation for the 13 mountain systems by comparing four different climate modes that summarize the joint changes in air temperature and precipitation over time. Based on a jointquantile approach described in detail by Beniston (2009), we used a combination of temperature and precipitation percentiles that display four modes of climate: warm and wet (WW), warm and dry (WD), cold and wet (CW) and cold and dry (CD). In order to secure a sufficient sample size for each climate mode, we selected the $30^{\text {th }}$ and $70^{\text {th }}$ quantiles as thresholds. More specifically, over the period 1960-2013 and for each grid, a particular year was classified as WW when the quantiles were above the $70^{\text {th }}$ quantile for both air temperature and precipitation, while it was denoted as CD when both quantiles were below the $30^{\text {th }}$ quantile. In a similar manner, each year was labeled as WD when the quantile thresholds were above $70^{\text {th }}$ for mean air temperature and below $30^{\text {th }}$ for precipitation. Likewise, the quantiles below $30^{\text {th }}$ for mean air temperature and above $70^{\text {th }}$ for precipitation characterized CW years. We compared the occurrence of the four climate modes (i.e., colddry, cold-wet, warm-dry and warm-wet) from 1960 to 2013 for the 13 mountain systems. For each mountain system, we assessed changes in the surface area represented by each climate mode using the OLS regression model, while their significance was tested at the 95\% confidence level. 


\section{Links between climate variability and atmospheric circulation patterns}

To provide a comprehensive picture of climate variability in the 13 mountain systems, we looked at the association between surface air temperature and precipitation and a range of large-scale circulation patterns, whose impacts are well-established at the global, hemispheric and even regional scale. Table 1 lists the selected circulation patterns used in this study. As indicated, the selected indices are mongest the most leading modes of interannual variability of sea surface temperature (SST) over the Atlantic (e.g. AMM, AMO, NAO, and EA), Pacific (e.g. MEI, WP, SOI, and NP) and Indian (e.g. Bombay, IOD) Oceans and the Mediterranean Sea (e.g. MOI and WeMOI), besides the surrounding regions. Also, while some large-scale climate drivers (e.g. the AO, AMM, EA, SCA and NAO) play a significant role in modulating regional climate variations over the Northern Hemisphere (Lopez-Moreno et al., 2011a, El Kenawy et al., 2012, 2016), other patterns (e.g. SO, MEI and IOD) could have more impact on climate in the Southern Hemisphere (Raut et al., 2014; Vicente-Serrano et al., 2017; Heino et al., 2018). Also, while some circulation patterns are characterized by a meridional oscillation between the atmospheric masses (e.g. NAO and AO), other patterns summarize zonal oscillations (e.g. MEI, SOI, AOI, MO, and WeMOI).

To account for the atmospheric configurations associated with climate variability in the 13 mountain systems, we linked annual surface air temperature and total precipitation with the circulation patterns listed in Table 1 for the period 1960-2013. To remove the climate change signal from the climatic data, we detrended the series of air temperature and precipitation at each gridpoint. A similar procedure was adopted in previous studies (e.g. Trenberth and Shea, 2005; El Kenawy et al., 2012, 2016). The strength of this association was assessed by means of the Pearson's coefficient of correlation and the statistical significance was evaluated using the modified Mann-Kendall statistic at the $95 \%$ confidence interval $(\mathrm{p}<0.05)$. Also, for the most significant circulation patterns for each mountain system, we extracted and compared the values of these circulation patterns for the four climate modes described in subsection 3.3.2. Following this approach, for each mountain system, we can define the phases (i.e. positive vs. negative) of the leading patterns, which are more favorable for the occurrence of specific climate modes.

\section{Results}

\subsection{Temporal evolution of surface air temperature}

Figure 3 depicts changes in surface air mean temperature for the 13 mountain systems for the period 1960-2013. Notably, all mountain systems exhibited a warming trend, with only few exceptions for some gridpoints in the Andes. Albeit with this overall temperature rise, there are some considerable differences among the mountain systems. As illustrated, the most rapid changes were observed for mountain systems located in the northern latitudes (i.e. Brooks and Kolyma). The amount of change was on the order of $0.45^{\circ}$ and $0.36^{\circ} \mathrm{C} / \mathrm{dec}$ ade for Brooks and Kolyma mountains, respectively. In the same context, temperature rise was generally more pronounced in the mid-latitudes mountains (e.g. the Alps, Pyrenees, Applach, Atlas and Himalaya), compared to those of the low latitudes (e.g. the Australian and Ethiopian mountains). Interestingly, the mountain systems located in the Southern Hemisphere witnessed weaker changes than those of the Northern Hemisphere. The amounts of change in the Andes $\left(0.04^{\circ} \mathrm{C} /\right.$ decade $)$ and the Australian $\left(0.15^{\circ} \mathrm{C} /\right.$ decade $)$ mountains were statistically insignificant at $\mathrm{p}<0.05$. A quick inspection of Figure 3 also suggests that the moderately elevated mountain systems $(<1000 \mathrm{~m})$ like the Brooks, Koylma and Scandinavian mountains experienced rapid warming than more highly elevated systems $(>1500 \mathrm{~m})$, such as the Andes, Himalaya, Rocky, Anatolia and Ethiopian mountains. Figure 3 also indicates that changes in the annual total precipitation were not spatially uniform among the different mountain systems. Although the majority of mountain systems exhibited a downwarding 
trend, they were statistically insignificant at the $95 \%$ confidence level $(\mathrm{p}<0.05)$. Interestingly, those mountains with statistically significant trends are located on the Atlantic Ocean (i.e. the Applach, Scandinavian and Pyrenees). While the Applach and Scandinavian mountains showed a statistically significant increase on the order of 20.35 and $26.99 \mathrm{~mm} / \mathrm{decade}$, respectively, the Pyrenees exhibited strong decline $(-38.01 \mathrm{~mm} /$ decade $)$.

Figure 4 illustrates the interannual variability of air temperature and precipitation anomalies, calculated with respect to the base period 1970-2000. For all mountain systems, we noted a sudden and strong increase in the mean air temperature over the past decades, mostly after 1985. As opposed, the earlier decades showed remarkable negative anomalies. The anomalous warm years were mainly assigned to the last two decades. For example, the largest positive anomaly was observed in 2011 in the Alps $\left(1.38^{\circ} \mathrm{C}\right)$, Pyrenes $\left(1.42^{\circ} \mathrm{C}\right)$ and Scandinavian $\left(1.56^{\circ} \mathrm{C}\right)$ mountains, compared to 2012 for the Rocky $\left(1.27^{\circ} \mathrm{C}\right)$ and 2013 for the Australian mountains $\left(0.89^{\circ} \mathrm{C}\right)$. As compared to other systems, the mega systems (e.g. the Andes, Rocky, and Himalaya) showed less interdecadal variability, with markedly lower deviations from the long-term mean. In comparison to air temperature, precipitation exhibited stronger interannual variability (Figure 5). This is clearly evident for all mountain systems, particularly for moderately elevated systems (e.g. the Atlas, Australian, Kolyma and Pyrenees). As opposed, the most elevated systems (e.g. the Rocky, Himalaya and Andes) showed less interannual variability; a similar pattern to that of air temperature (refer to Figure 4).

In an attempt to define the common patterns of temporal variability of surface air temperature among the different mountain systems, we applied the principal components analysis (PCA) in T- mode, as a data reduction technique, enhanced by a orthogonal rotation method (varimax rotation) (Wilks, 2011). Based on the scree plot results, we found three components that accounted together for $72.7 \%$ of the total explained variance of air temperature (Figure 6). Each component describes a common pattern of interannual and interdecadal variability of air temperature that is shared by a range of mountain systems. As depicted, all components showed positive loadings, suggesting that temperature rise is a global phenomenon among all mountain environments. The first component (PC1) contributed to $28.5 \%$ of the total variance, and reflected the temporal evolution of surface air temperature in almost half of the mountain systems, including Anatolia, Applach, Atlas, Himalaya, Kolyma, and Rocky. All these mountainous terrains showed strong positive changes in surface air temperature, particularly in the last two decades, compared to a remarkable below-normal temperature during the 1960s, 1970s and 1980s. The second component (PC2) explains $24.3 \%$ of the total variance and summarizes air temperature variability in the mountains of southern (i.e. the Alps and Pyrenees) and northern Europe (i.e. Scandinavian mountain). This component shows the strongest temporal variability among all systems $(0.37 \% \mathrm{z}$ units/decade), which is mainly associated with the rapid temperature rise from late 1980s onwards. The third component (PC3) explains $20 \%$ of the total variance, and is best correlated with air temperature variability in the Andes, Brooks, Ethiopian and Australian mountains. Apart from Brooks, these mountains belong to the tropics, subtropics and the Southern Hemisphere, with the lowest warming rate among all components.

PCA produced six components accounting for $68.6 \%$ of the total variance of annual precipitation, but with no individual component explaining more than $15 \%$ of the total variance (Figure 7). This clearly suggests that precipitation shows higher temporal variability than air temperature. As opposed to air temperature, most of the defined components of precipitation variability show a statistically insignificant trend from 1960 to 2013 ( $p>0.05$ ). Exceptionally, the first component (PC1), which is most closely correlated with precipitation variability over the Alps, Pyrenees and Scandinavian mountains, exhibited the strongest and most significant changes among all systems. Notably, these European mountains show a 
contrasted behavior along this component, with a statistically significant decrease in total precipitation over the Alps and the Pyrenees in southern Europe, compared to a strong increase over the Scandinavian mountains in northern Europe. The fifth component (PC5) also exhibits statistically significant changes in total precipitation. However, it is only best correlated with precipitation variability over the Applach system, suggesting above-normal precipitation, especially from the mid of 1990 s onwards. For other components (i.e. PCs 2,3,4, and 6), results suggest a decrease in total precipitation, though being statistically insignificant at $\mathrm{p}<0.05$. As illustrated in Figure 7 , the temporal evolution of precipitation in mountain systems belonging to these components is characterized by higher interannual variability, as compared to PC1 and PC5. A quick comparison of the defined components for air temperature and precipitation indicates that the European mountains belonged to very similar regional groupings (i.e. PC2 for air temperature and PC1 for precipitation), suggesting that there is a temporal consistency in climate evolution across these mountains over the past decades.

\subsection{Dependency of temperature and precipitation trends on topographical and latitudinal characteristics}

We also looked at the association between changes in air temperature and precipitation and elevation for each mountain system. Scatter plots summarizing this association are illustrated in Figures 8 and 9. Results reveal two contradictory patterns for air temperature (Figure 8). Interestingly, we noted that - for mountainous regions with larger warmingchanges in air temperature tend to be generally stronger as elevation increases. This pattern is evident for the mountains of high- (e.g. Kolyma, Scandinavian) and mid-latitudes (e.g. Alps and Pyrenees) of the Northern Hemisphere, suggesting that highly-elevated sites of these mountains are more vulnerable to accelerated warming than low and mid-elevations. A contradictory pattern is observed for those mountains with weaker changes of air temperature, as temperature trends either do not vary considerably as a function of varying elevations (e.g. Anatolia, Australian, Himalaya and Rocky) or tend to decrease at higher elevations (e.g. Ethiopian and Andes). These two patterns clearly indicate that the great component of the overall warming rate at complex terrain regions comes from accelerated temperature at the most elevated sites. Figure 9 informs on the dependence of changes in annual precipitation on elevation. Apart from the Pyrenees, all mountain systems exhibited a mixture of negative and positive changes of precipitation, suggesting strong spatial variability of precipitation changes in mountainous regions. Overall, for most mountain systems, positive changes are found at low elevations, while higher elevations tend to exhibit negative changes. This dependency can be expected, given the linear association between elevation and rainfall amounts. In particular, higher elevations often receive larger amounts of precipitation than low sites and accordingly they are more sensitive to even small changes in annual precipitation. Figure 9 confirms this dependency for all mountains systems worldwide, apart from Himalaya and Kolyma, where a reversed pattern can be seen (i.e. negative changes at lower elevations and positive changes at higher elevations). Again, Figure 9 suggests that -for the majority of mountain systems- highly elevated sites are more prone to climate change, with more tendencies to lower precipitation in recent decades.

For mountain systems with larger latitudinal extension (i.e. Rocky and Andes), we explored changes in air temperature and precipitation as a function of latitude. As illustrated in Figure 10, for the Andes and Rocky, there is a general tendency toward enhanced warming for latitudes beyond the tropic and subtropics, compared to relatively less pronounce warming in lower latitudes. In comparison to air temperature, the latitudinal gradient of precipitation changes is more apparent. For the Andes, the decrease in precipitation is markedly weak in the tropical and subtropical zone, while this decrease is markedly much stronger in temperate latitudes $\left(37-47^{\circ} \mathrm{S}\right)$. A reversed pattern is noted for the Rocky, where 
more pronounced changes are observed in lower latitudes (south of $40^{\circ} \mathrm{N}$ ), compared to weaker changes in latitudes northward. Again, Figure 10 reveals that while temperature rise seems to be well-verified for the Rocky and Andes, with less variability among latitudes, precipitation changes are more variable with stronger gradients among latitudes.

\subsection{Covariability of air temperature and precipitation}

Table 2 summarizes the spatial consistency between the different trend categories of air temperature and precipitation for each mountain system (i.e. statistically significant positive $[+]$, statistically significant negative [-], statistically insignificant positive [N+], and statistically insignificant negative $[\mathrm{N}-]$ ). Results demonstrate that, for all mountain systems, there is a low agreement between changes in surface air temperature and those of precipitation. This is revealed in the lowest cumulative frequency of the diagonal cells of each contingency table, compared to the total frequency of all cells. Notably, for all mountain systems, there is an absence of statistically significant decrease either in air temperature or precipitation. The dominating positive trend of air temperature in all mountain regions is mostly associated with either a statistically insignificant increase (e.g. Applach, Himalaya, Kolyma, and Scandinavian mountains) or decrease (e.g. the Alps, Australian, Brooks, Ethiopian, Pyrenees, and Rocky mountains) in total precipitation. As compared to other mountainous regions, those located along the Atlantic Ocean (i.e. the Applach and Scandinavian systems) show improved spatial consistency, where more than $40 \%$ of gridpoints exhibited statistically significant concurrent trends for air temperature and precipitation. In particular, the two categories $[+/+]$ and $[+/ \mathrm{N}+]$ of [air temperature/precipitation] accounted together for $98.5 \%$ of all gridpoints for the Scandinavian system, compared to $84.8 \%$ for the Applach. This suggests that temperature rise in these mountain systems is mostly associated with precipitation increase, though oftentimes not being statistically insignificant. The Pyrenees shows a remarkable pattern, with all gridpoints exhibiting statistically significant positive changes in air temperature, accompanied by a statistically insignificant decrease in total precipitation.

We also looked at the association between air temperature and precipitation using the four climate modes derived by means of a joint quantile approach (section 3.2.2). In this work, the four climate modes included: cold and dry $(\mathrm{CD}: \mathrm{T}<30, \mathrm{P}<30)$, cold and wet $(\mathrm{CW}$ : $\mathrm{T}<30, \mathrm{P}>70$ ), warm and dry (WD: $\mathrm{T}>70, \mathrm{P}<30$ ) and warm and wet (WW: T> 70, P> 70). Table 3 summarizes changes in the total surface area represented by each climate mode for the 13 mountain systems from 1960 to 2013. Results demonstrate a statistically significant decrease in the area represented by the CD and CW modes, and conversely a statistically significant increase in the areas witnessed the WD and WW modes. These patterns indicate clearly that air temperature rise is the key variable driving climate variability in mountainous regions. For cold-dry (CD) mode, the strongest decrease is found for the Scandinavian $(-4.2 \% /$ decade), Applach (-3.4\%/decade), Alps (-3.4\%/decade), Himalaya (-3.2\%/decade), and Brooks ($3.1 \% /$ decade), meanwhile the weakest decrease is found for the Pyrenees (-0.7\%/decade) and the Andes (-1.1\%/decade). The rapid decrease in CD over the Scandinavian and Applach mountains is mainly associated with the increase in wet conditions over the past decades, while the strong decrease across the Alps, Himalaya and Brooks is linked particularly to temperature rise (Figure 3). A comparison between changes in the $\mathrm{CD}$ and $\mathrm{CW}$ modes reveals that - in comparison to other mountain regions- changes in CW mode over the Applach and Scandinavian systems are markedly less pronounced than those of CD. This demonstrates that the significant increase in precipitation over the Applach and Scandenavia contributes to modulating the accelerated warming in these regions. In contrast, the stronger changes in $\mathrm{CW}$ mode compared to CD mode, especially for the Pyrenees, Ethiopian, and Alps, indicate that the accelerated warming is enhanced by a precipitation deficit over the last decades. This 
feature is also confirmed by the strong increase in the area affected by WD : $7.0 \% /$ decade (Pyrenees) and 5.2\%/decade (Alps).

\subsection{Links to circulation patterns}

This study also assessed the role of a set of regional, hemispheric and global circulation patterns in determing the response of mountain systems to recent climate variability. Figure 11 summarizes the correlation between circulation indices and surface air temperature. As illustrated, there are strong variations in the dependency between temperature variability and circulation patterns, but with remarkable patterns: (i) the warm phase of the AO is the key driver of temperature variability over the European mountains (e.g. Alps, Pyrenees and Scandinavian), (ii) the impacts of the NAO on temperature variability is mainly restricted to the Mediterranean and the North Atlantic mountains, albeit with different phases (i.e. warm for the Alps, Pyrenees and Scandinavian, and cool for the Anatolia, Applach, and Atlas), (iii) the NAO impacts on temperature variability in the Mediterranean and the North Atlantic mountains are superior compared to other Atlantic indices (e.g. AMM and AMO), (iv) the warm phase of the EA can significantly describe temperature rise over the Mediterranean mountains (e.g. Pyrenees, Atlas, and Anatolia), (v) temperature variability in the Kolyma mountain is mainly driven by the cool phase of the WP, (vi) the multivariate ENSO (MEI) is the dominant pattern impacting temperature variability in mountains of the Southern Hemisphere (i.e. Andes and Australian) and the tropics (i.e. Ethiopian); however, its impacts are apparently minimized over the mountains of the Northern Hemisphere, (vii) temperature variability in mountains of the Southern Hemisphere is linked significantly to the cool phase of the SI, and (viii) there is no individual pattern that mostly drive temperature variability in the "mega" systems like the Himalaya and Rocky, but there is probably a coexisting influence of different patterns.

Figure 12 illustrates the dependency between precipitation and circulation patterns for the 13 mountain systems. Similar to air temperature, precipitation variability in the largest mountains (e.g. Himalaya, Rocky and Andes) cannot be explained by the evolution of specific circulation patterns. Nonetheless, the possible coexisting impact of different circulation patterns on precipitation variability in these mega systems extends further to other mountain systems (e.g. Applach, Brooks, and Ethiopian mountains). As illustrated in Figure 12 , it can be noted that (i) the negative phase of the SCA is a key driver of precipitation variability over Scandinavian mountains (northern Europe), while its positive phase is linked to precipitation variations over the Pyrenees (southern Europe), (ii) the decrease in precipitation over the Pyrenees is also associated with the negative phase of the MOI, (iii) the positive phase of the SOI is the dominant pattern influencing precipitation variability over the Australian mountains, (iv) precipitation variability over the Atlas is mainly driven by the negative phase of the EA, (v) precipitation variations in Kolyma system is more linked to the positive phase of the NP, and (vi) notably, precipitation variability in majority of the mountainous regions did not show significance dependence on circulation patterns that are well-recognized as key drivers of climate variability at the global scale (e.g. MEI, AMM, and AO).

Figure 13 illustrates variations in the values of the best-correlated circulation patterns for each mountain region, averaged for the four defined climate modes (i.e. CD, CW, WD and WW), compared to the mild conditions (i.e. $30<\mathrm{T}<70,30<\mathrm{T}<70$ ), while Table 4 summarizes the dominant phase of each circulation pattern, associated with each climate mode. As listed in Table 4, it can be seen that only few circulation patterns (e.g. AMM, AMO, Bombay), which show stationary patterns of dependency with climate modes. For example, the negative phase of AMM is responsible for the occurrence of $\mathrm{CD}$ and $\mathrm{CW}$ conditions in Anatolia, Applach, Atlas and Himalaya, while its positive phase is best correlated with WD and WW conditions. However, in many occasions, each individual circulation pattern shows different 
patterns of dependency with the different modes of climate. A representative example is the negative phase of the NAO, which can explain the occurrence of CD and CW in the Alps and Scandenavia, while it is associated with WD and WW in Anatolia. This suggests that there is a high degree of complexity in the impact of the same circulation pattern on climate modes from one mountain system to another.

\section{Discussion and conclusions}

Mountainous regions are amongst the most sensitive regions to climate change (Beniston et al., 1997; Buytaert et al., 2006; Beniston, 2009; Gobiet et al., 2014). However, a comprehensice assessment of the extent to which these regions are affected by warming climate is apparently lacking, especially from a global perspective. The intent of this work is to compare and contrast changes in surface air temperature, annual total precipitation and their combined modes for the main mountainous terrain systems over the world. To accomplish this task, we assessed changes in these climate variables using monthly data from CRUTS-v3.22 for a 58-timeframe (1960-2017) across 13 mountain systems (i.e. the European Alps, Anatolia, Andes, Applach, Atlas, Australian, Brooks, Ethiopian, Himalaya, Kolyma, Rocky, Pyrenees, and Scandinavian). These systems span the low-, mid- and highlatitudes of the Northern and Southern Hemispheres. This work also gives insights into the key circulation patterns controlling climate variability in these complex terrain regions and explore whether the dominant circulation patterns show consistent dependency with the different climatic modes.

Assessing spatiotemporal trends of climate is a high priority of climate change studies, particularly in mountainous terrain regions (Beniston, 2009; Barriopedro et al., 2011; IPCC, 2013). This study demonstrates that all mountainous regions from the equatorial to the high latitudes experience an upward trend in surface air temperature over the period 1960-2013, suggesting that temperature rise is a global phenomenon. Notably, majority of the mountainous terrain regions witnessed warming rate clearly stronger than the global warming rate. This can simply be seen in the context that warming in areas of complex terrain is apparently stronger than lowlands. For example, Trenberth et al. (2007) found larger amount of warming over mountainous regions in the western and southwestern US, compared to the whole Northern America. As per the Fourth Assessment Report (AR4) of the Intergovernmental Panel Climate Change (IPCC), the global mean surface temperatures have risen by $0.74^{\circ} \mathrm{C}$ in recent century (IPCC, 2007), particularly in the last 50 years during which the warming rate has been doubled $\left(0.13^{\circ} \mathrm{C} /\right.$ decade). We found stronger warming changes in surface air temperature, on the order of $0.45^{\circ}, 0.36^{\circ}, 0.32^{\circ}, 0.29^{\circ}, 0.24^{\circ} \mathrm{C} / \mathrm{decade}$ for Brooks, Kolyma, Alps, Pyrenees and the Applach mountains. Among all mountain systems, the Andes is the only mountainous region that exhibited weaker warming $\left(0.04^{\circ} \mathrm{C} / \mathrm{decade}\right)$, compared to the global warming rate. Our study reveals some remarkable differences among the terrain systems. For example, we noted stronger warming in mountains of the highlatitudes in the Northern Hemisphere (e.g. Brooks, Kolyma and Scandinavian) than those of the mid- and low-latitudes. A similar finding has been confirmed in earlier studies (e.g. Serreze et al., 2000; Knowles et al., 2006). Serreze et al. (2000) reported a pronounced temperature rise in the northern high-latitudes regions from 1970 onwards, being more evidenced during wintertime. This warming caused negative snow cover anomalies over Alaska and northern Russia, combined with increased plant growth, greater shrub abundance and northward migration of the tree line. Herein, it is important to note that mountain environments (e.g. Brooks, Kolyma, Alps and Pyrenees), which witnessed strong air temperature warming are of low or mid-elevations $(<1500 \mathrm{~m}$, refer to Figure 2$)$, while highelevation regions (e.g. Andes and Himalaya) exhibited weak and statistically insignificant temperature rise. This finding is important as warmer temperatures at mid-elevations can decrease snowpack, leading to a decline in snowpack accumulation and earlier melt, 
particularly in those regions with precipitation decrease (e.g. Alps, Pyrenean, and Ethiopian mountains). According to Beniston (1997), mountains with seasonal snowpack (e.g. midlatitudes mountains) are more sensitive to global warming, as even small temperature increase can impact snowpack extension. On the other hand, the most elevated regions can remain below freezing for a longer time, as a consequence of the longer snow.

Our study also demonstrates that changes in precipitation over regions of complex terrain were heterogeneous, with some regions experiencing positive changes (e.g. Applach and Scandinavian), while others exhibiting negative changes (e.g. Alps, Pyrenees, and Ethiopian mountains). Nonetheless, changes in the annual precipitation were generally statistically insignificant ( $p>0.05$ ) for majority of the mountain systems, particularly those located in the Southern Hemisphere and northern low-latitudes. Interestingly, our results reveal that northern high-latitude mountains either experienced statistically significant increase in annual total precipitation (e.g. Scandinavian and Applach mountains) or weak changes (e.g. Brooks and Kolyma) over the past several decades. A similar finding was reported by the IPCC (2007), indicating significant precipitation increases over the last century in the eastern portion of North America, northern Europe, and northern and Central Asia. This finding may suggest that changes in air temperature have greater relative importance than those of precipitation over most of the mountainous regions. Specifically, the strong warming of air temperature in the Alps, Brooks, Kolyma and Pyrenees mountains corresponds to a generally decreasing trend of precipitation, though being statistically significant only for the Alps and Pyrenees $(\mathrm{p}<0.05)$. As such, the natural capacity of these mountainous regions to store water until drier seasons (e.g. late spring and summer) can be diminished, given the weak and even negative moisture supply. For other complex terrain regions (e.g. Scandenavia), the impacts of a modest amount of warming $\left(0.24^{\circ} \mathrm{C} /\right.$ decade $)$ may be masked by the strong increase in precipitation increase $(27 \mathrm{~mm} /$ decade), leading to a delay in snow melting and streamflow timing. Brown (2000) demonstrates that precipitation increases on the order of $2 \%$ are sufficient to offset the impacts of warming in snow-dominated regions. Again, this suggests that -apart from norther high-latitudes systems- change in air temperature is the dominant factor, with more impacts on ecosystems, compared to those of precipitation. A similar finding is confirmed by Korner (1998) who found that change in air temperature is the primary factor influencing ecosystem in most mountainous regions worldwide.

Overall, air temperature and precipitation changes clearly suggest that mountains of the northern high-latitudes - and to a lesser extent the mid-latitudes- are more vulnerable to rapid ecological and hydrological changes than other global terrain systems, particularly those in the Southern Hemisphere and the subtropics. Unfortunately, model projections suggest that this warming is likely to increase and accelerate in the future, adding further complications and challenges to these regions. Based on climate model outputs, Nogués-Bravo et al. (2007) indicated that air temperature is projected to increase in the mid and late $21^{\text {st }}$ century, but at a greater amount in mountainous terrain in northern latitudes of the Northern Hemisphere than mountains located in temperate and tropical zones. The discernible and critical impacts of increased warming may include changes in available water supply from snowpacks (e.g. Paul, 2011; Bolch et al., 2012; Pellicciotti et al., $201 \varepsilon$ ), vegetation distribution and growth (e.g. Keller et al., 2005; Gottfried et al., 2012), species structure, and timing and availability of runoff (e.g. Stewart, 2009; Rohrer et al., 2013). For example, the environmental impacts of accelerated temperature in these systems can limit the survival of their fauna and flora and induce their rapid shift to higher altitudes, seeking for more favorable habitats in terms of climatic conditions. In their global investigation of the latitudinal range shifts of a range of taxonomic groups, Chen et al. (2011) found a positive shift of 11 meters/decade for some species ranges in the Northern Hemisphere, in response to recent warming. Hydrologically, the significant decrease in annual precipitation in the mid-latitudes mountains, particularly 
the European mountains (e.g. the Alps, Pyrenees), combined with a strong temperature rise and thus atmospheric evaporate demand (AED) can enhance the reduction in annual streamflow. These hydrological impacts have been evidenced in Beniston $(2003,2009)$ for the European Alps and in Lorenzo-Lacruz et al. (2012) for the Pyrenees. Under the climate warming, the spatial extent of snow cover in the Northern Hemisphere has also decreased by almost 5.4\% from 1972 to 2006, mainly driven by temperature rise, especially during springtime (Déry and Brown, 2007; Brown and Robinson, 2011). More recently, Hammond et al. (2018) found that snow persistence, expressed as the fraction of a year with permanent snow coverage, showed a decreasing trend over $5.8 \%$ of snow zone areas over the globe, compared to areas of $1.0 \%$ with decreasing trends. Similarly, Hamlet et al. (2005) indicated that temperature change in the western United States is the primary factor responsible for most of large-scale declines in snowpack as well as shifts in snowmelt runoff. Nonetheless, it is noteworthy indicating that the vertical distribution of fauna and flora in response to recent and future climatic variability can vary at regional and even local scales, as a consequence of topographic characteristics (e.g. slope, aspect, orientation), soil properties, vegetative effects, and several abiotic factors (Lenoir et al 2013; Millar et al 2014). Strachan et al. (2016) demonstrate that the response and resistance of species distribution over complex terrain is largely driven by "topoclimates" and "microclimates" rather than broad climatic conditions. This is simply due to the strong climatic gradients over short distances, which can strength the role of some local factors (e.g. cold air pooling and inversions), making it difficult to capture climate variability across spatial and temporal scales. Although the reduction in snow cover can contribute further to global warming, given the high albedo of fresh snow and its significant contribution to the global heat budget (Serreze et al., 2000), the impact of warming on snowpack reduction depends largely on geographic location, latitude, and elevation, and can thus vary considerable from mountainous region to another. The earlier snowmelt can enhance warming of soils, increase growing season length and atmospheric evaporative demand (Peterson and Peterson, 2001).

This study defined three main components that explain a a maximum of $72.72 \%$ of the variability in surface air temperature across the global mountainous terrain, compared to six components that accounted for $68.59 \%$ of the variability of annual precipitation. The higher number of components and their corresponding lower explained variance for precipitation can be expected, as precipitation is one of the most difficult climate variables to be spatially captured. As compared to temperature, precipitation shows stronger spatial and temporal variability over complex terrain, as it is not only coupled to large-scale synoptic conditions, but it is driven by local topographical predictors (e.g. aspect, slope, orientation, altitude, coastal proximity) as well. In this contest, the density of rain gauges is generally sparse in mountainous regions either horizontally or vertically. Most of rain gauges are located in valleys or at low altitudes, leading to a clear underestimation of precipitation, especially at high altitudes, which normally receive the highest amounts of rainfall (Palazzi et al., 2013; Maussion et al., 2014). The temporal evolution of air temperature and precipitation for some extracted components agree well with previous works. An example is the pronounced temperature rise from 1980 onwards, which is noted for the European mountains (i.e. the Alps, Pyrenees and Scandinavian). This pattern has been evidenced by El Kenawy et al. (2012) for the Pyrenees and by Beniston $(1997,2003,2009)$ and Beniston et al. (1997) for the European Alps.

Assessing the response of mountainous environments to climate variability is a challenging task. Herein, we should be aware of the sources of uncertainty associated with selecting CRUTS-v3.22 as a reference database for our analysis. In mountainous terrain, assessing signals of climate change based on CRUTS-v3.22 has a degree of uncertainty, due to the spatial resolution of this product $\left(0.5 \times 0.5^{\circ}\right.$ degree $)$, which is relatively coarse to 
resolve orographic complexity and their associated climatic variations in these regions. Furthermore, according to Mitchell and Jones (2005), CRUTS-v3.22 was developed using a quite low number of applied stations at mountainous territories worldwide. This feature may lead to high grid-box sampling uncertainty and accordingly an inadequate representation of the strong gradients of climate, particularly at higher altitudes with low sampling of observational data (Matthews et al., 2017). Independent of the selected dataset, this feature is definitely reflected in all gridded climate datasets built on observations, especially in those regions with sparse observational coverage like remote and complex terrain. Yin et al. (2015) noted that gridded products in regions with complex terrain can be impacted by station density over space and time, particularly when aggregating from point to grid scale. To resolve their complex climatic variability, Lundquist and Cayan (2007) stress that a proper characterization of spatial and temporal variability over mountainous regions requires dense networks of sensors, with high temporal resolution. Similarly, Sexstone et al. (2016) confirm that modeling climate variability is a challenging task in complex mountainous systems, given that this variability occurs over relatively short distances on one hand and there exist difficulties in representing within-grid processes, particularly those related to the mass and energy exchange between land and atmosphere, on the other hand. For example, in their study over the Cascade Mountains, Minder et al. (2010) found strong spatial and temporal variability of surface temperature lapse rate depending on the aspect and the slope.

Another source of uncertainty in gridded climate datasets, including CRUTS-v3.22, is related to the various assumptions of the selected interpolation algorithm, particularly in regions of sparse horizontal and vertical distribution of observations. Albeit with its relatively dense network of rain gauges, Masson and Frei (2014) noted that the climatology of precipitation in the European Alps can differ significantly, as a function of the selected interpolation/extrapolation method. A similar finding is confirmed for other mountainous terrain, such as the Himalaya (e.g. Kumari et al., 2016), the Andes (e.g. Buytaert et al., 2006) and the Appalachian (e.g. Bolstad et al., 1998) mountains. Similarly, most of the climate models used for future projections, either global climate models (GCMs) or those dynamically downscaled by regional climate models (RCMs) (Fowler et al., 2007), show large uncertainties over mountainous regions, when compared with near-present climate conditions (Maraun et al., 2010). Indeed, in mountainous terrain, installation and maintance of meteorological stations is costly and under-catch, especially at higher altitudes. As such, the density of the network of meteorological data in these regions is markedly low due to poorly-sited instruments, representing the key limitation of climate assessment and modeling in mountainous regions. This uneven distribution of meteorological observatories fails to resolve uncertainties associated with the complex variability of climate and the existence of non-linear feedbacks between climate and topography. Palazzi et al. (2013) and Maussion et al. (2014) reported that, regardless of dataset choice, there exists an underestimation of precipitation at high elevated sites, which can be seen in the context of the general increase of precipitation with altitude combined with the low sampling of stations at highly elevated sites. Several studies highlighted the disagreement between gridded climate products in complex terrain regions at different ecological and hydrological scales (e.g. Stahl et al 2006; Minder et al 2010). Furthermore, climate shows low spatial coherence and high variance over areas of complex topography. Accordingly, trends can vary considerably among valleys, summits, slopes, mountain passes, and above glaciers, even at a subgrid scale. These local features can have distinctive characteristics that strongly impact local climate in ways that may not be representative of the larger terrain. In mountainous regions, it is also quite difficult to guarantee spatial and temporal homogeneity of climatic data in mountainous regions. For example, it is difficult to maintain uniform-height measurements during changing snowpack conditions (Marks et al., 2013). Indeed, some alternative datasets (e.g. 
GPCC, GPCP, UDEL, PRECL...etc) can either offer better station network density on the global scale, merge instrumental data with satellite estimates, or have higher spatial resolution (Tanarhte et al., 2012). Nonetheless, in comparison to these products, CRUTSv3.22 is more advantageous in the sense that it provides data for air temperature and precipitation at a consistent spatial interval $\left(0.5^{\circ}\right.$ degree $)$ over the globe. Furthermore, climatic data are available over extended periods of multiple decades, allowing for more reliable assessment of long-term climate variability. However, it is also noteworthy indicating that the observed patterns of changes in surface air temperature and precipitation over the regions of complex topography may vary considerably from one dataset to another. Previous works reveal substantial differences amongst the gridded datasets, demonstrating that the uncertainty and the spread amongst these multiple datasets can vary considerably among regions and seasons (Kim et al., 2015; Kim and Park, 2016). However, a detailed assessment of the uncertainty in climate signals over regions of complex terrain, as a function of the selected global gridded dataset, can be an avenue for future research to explore inter-dataset differences. Herein, it is also important to emphasize that our results presented here should be used with caution when studying climate variability and their impacts on more regional and local scales (e.g. local ecology, runoff modelling, and species structure). This can be seen in light of high complexity of terrain and their associated strong climatic gradients, which necessitates dense observations, particularly at high altitudes, to provide more "realistic" local climate estimates for heterogeneous regions. Recalling this complexity and heterogeneity, any adaptation and mitigation strategies to cope with the impacts of climate variability and change must be acted locally to account effectively for high local variations. As such, the role of CRUTS-v3.22's relatively coarse horizontal resolution should be kept in mind when interpreting results of this work.

While there are several studies assessing spatial and temporal characteristics of climate in individual mountain systems and their links to tree growth (e.g. Peterson and Peterson, 2001), species structure (e.g. Gottfried et al., 2012; Alagador et al., 2014), snowpack and flooding (e.g. Brown and Robinson, 2011), forest fire (e.g. Návar and Lizárraga-Mendiola, 2013) and even human influences (e.g. Bonfils et al., 2008), our study may be unique, in the sense that it provides -for the first time- a global perspective of climate variability in a wide range of mountain systems with different latitudinal, topographical and climatic characteristics. As such, this work provides a framework for comparing climate modes between the main global mountain systems, highlighting their spatial and temporal differences. This study also provides a solid base for filling crucial gaps in current understanding of mountain processes and the response of global mountain regions to rapid and sustained changes in temperature and precipitation regimes. Moreover, this global perspective can serve as a reference frame for several regional assessments. This assessment can also contribute to sustainable development in mountain environments, given that these regions represent an important part of the terrestrial environment, with rapid hydrologic, geomorphic and socio-economic changes. Our results can improve current understanding of these vulnerable ecosystems to climatic variability and accordingly adopt appropriate adaptation strategies and plans for these mountain systems.

\section{Acknowledgements}

This work was supported by the research project I-Link1001 (Validation of climate drought indices for multi-sectorial applications in North America and Europe under a global warming scenario) financed by CSIC, PCIN-2015-220 and CGL2014-52135-C03-01 financed by the Spanish Commission of Science and Technology and FEDER, IMDROFLOOD financed by the Water Works 2014 co-funded call of the European Commission and INDECIS, which is part of ERA4CS, an ERANET initiated by JPI Climate, and funded by FORMAS (SE), DLR (DE), BMWFW (AT), IFD (DK), MINECO (ES), ANR (FR) with co-funding by the European Union (Grant 690462). 


\section{References}

Alagador D, Cerdeira JO, Araújo MB. 2014. Shifting protected areas: scheduling spatial priorities under climate change. J. Appl. Ecol., 51, 703-713.

Barnett TP, Adam JC, and Lettenmaier DP. 2005. Potential impacts of a warming climate on water availability in snow-dominated regions. Nature 438:303.

Barriopedro D, Fischer EM, Luterbacher J, Trigo RM, and García-Herrera R. 2011. The Hot Summer of 2010: Redrawing the Temperature Record Map of Europe. Science 332(6026):220-224.

Beniston M. 1997. Variations of snow depth and duration in the Swiss Alps over the last 50 years: Links to changes in large-scale climatic forcings. Climatic Change 36: 281300 .

Beniston M, Diaz HF, Bradley RS. 1997. Climatic change at high elevation sites: an overview. Clim Change 36:233-251.

Beniston M. 2003. Climatic change in mountain regions: a review of possible impacts. Clim Change ;59:5-31.

Beniston M. 2009. Trends in joint quantiles of temperature and precipitation in Europe since 1901 and projected for 2100. Geophysical Research Letters 36(7).

Bolch T, Kulkarni A, Kääb A, Huggel C, Paul F, Cogley JG, Frey H, Kargel JS, Fujita K, Scheel M et al. . 2012. The State and Fate of Himalayan Glaciers. Science 336(6079):310-314.

Bolstad PV, Swift L, Collins F, and Régnière J. 1998. Measured and predicted air temperatures at basin to regional scales in the southern Appalachian mountains. Agricultural and Forest Meteorology 91(3):161-176.

Bonfils C, Santer BD, Pierce DW, Hidalgo HG, Bala G, Das T, Barnett TP, Cayan DR, Doutriaux C, Wood AW et al. . 2008. Detection and Attribution of Temperature Changes in the Mountainous Western United States. Journal of Climate 21(23):64046424.

Brown RD. 2000. Northern Hemisphere Snow Cover Variability and Change, 1915-97. Journal of Climate 13(13):2339-2355.

Brown RD, Robinson DA. 2011. Northern Hemisphere spring snow cover variability and change over 1922-2010 including an assessment of uncertainty. The Cryosphere 5: 219-229.

Burke MB, Miguel E, Satyanath S, Dykema JA, and Lobell DB. 2009. Warming increases the risk of civil war in Africa. Proceedings of the National Academy of Sciences 106(49):20670-20674.

Buytaert W, Celleri R, Willems P, Bièvre BD, and Wyseure G. 2006. Spatial and temporal rainfall variability in mountainous areas: A case study from the south Ecuadorian Andes. Journal of Hydrology 329(3):413-421.

Chen B, Chao WC, and Liu X. 2003. Enhanced climatic warming in the Tibetan Plateau due to doubling CO2: a model study. Climate Dynamics 20(4):401-413.

Chen I-C, Hill JK, Ohlemüller R, Roy DB, and Thomas CD. 2011. Rapid Range Shifts of Species Associated with High Levels of Climate Warming. Science 333(6045):10241026.

Déry SJ and RD Brown. 2007. Recent Northern Hemisphere snow cover extent trends and implications for the snow-albedo feedback. Geophysical Research Letters 34(22).

El Kenawy A, López-Moreno JI, and Vicente-Serrano SM. 2012. Trend and variability of surface air temperature in northeastern Spain (1920-2006): Linkage to atmospheric circulation. Atmospheric Research 106:159-180. 
El Kenawy AM. and McCabe MF. 2016. A multi- decadal assessment of the performance of gauge- and model- based rainfall products over Saudi Arabia: climatology, anomalies and trends. Int. J. Climatol., 36: 656-674.

El Kenawy AM, McCabe MF, Vicente-Serrano SM, Robaa SM, and Lopez-Moreno JI. 2016. Recent changes in continentality and aridity conditions over the Middle East and North Africa region, and their association with circulation patterns. Climate Research 69(1):25-43.

Fowler HJ, Blenkinsop S. and Tebaldi C. 2007. Linking climate change modelling to impacts studies: recent advances in downscaling techniques for hydrological modelling. International Journal of Climatology 27(12):1547-1578.

Fyfe JC, and Flato GM. 1999. Enhanced Climate Change and Its Detection over the Rocky Mountains. Journal of Climate 12(1):230-243.

Gaudard L, Romerio F, Dalla Valle F, Gorret R, Maran S, Ravazzani G, et al. 2014. Climate change impacts on hydropower in the Swiss and Italian Alps. Sci Total Environ, 493: 1211-1221.

Giorgi F, Hurrell JW, Marinucci MR, and Beniston M. 1997. Elevation Dependency of the Surface Climate Change Signal: A Model Study. Journal of Climate 10(2):288-296.

Gobiet A, Kotlarski S, Beniston M, Heinrich G, Rajczak J, and Stoffel M. 2014. 21st century climate change in the European Alps-A review. Science of The Total Environment 493:1138-1151.

Gottfried M, Pauli H, Futschik A, Akhalkatsi M, Barančok P, Benito Alonso JL, Coldea G, Dick J, Erschbamer B, Fernández Calzado MaR et al. . 2012. Continent-wide response of mountain vegetation to climate change. Nature Climate Change 2:111.

Hamed KH and Rao R. 1998. A modified Mann-Kendall trend test for auto-correlated data. Journal of Hydrology, 204, 182-196.

Hamlet AF, Mote PW, Clark MP, and Lettenmaier DP. 2005. Effects of Temperature and Precipitation Variability on Snowpack Trends in the Western United States. Journal of Climate 18(21):4545-4561.

Hammond JC, Saavedra FA, Kampf SK. 2018. Global snow zone maps and trends in snow persistence 2001-2016. Int J Climatol.;1-15.

Harris I, Jones P, Osborn T. and Lister D. 2014. Updated high-resolution grids of monthly climatic observations - the CRU TS3.10 Dataset. International Journal of Climatology 34(3):623-642.

He S, Wang D, Fang Y, and Lan H. 2017. Guidelines for integrating ecological and biological engineering technologies for control of severe erosion in mountainous areas - A case study of the Xiaojiang River Basin, China. International Soil and Water Conservation Research 5(4):335-344.

Heino M, Puma MJ, Ward PJ, Gerten D, Heck V, Siebert S, and Kummu M. 2018. Twothirds of global cropland area impacted by climate oscillations. Nature Communications 9(1):1257.

Hoffman AL, Kemanian AR, Forest CE. 2018. Analysis of climate signals in the crop yield record of sub- Saharan Africa. Glob Change Biol.;24:143-157.

IPCC. 2007. In Climate Change 2007: Synthesis Report. Contribution of Working Groups I, II and III to the Fourth Assessment Report of the Intergovernmental Panel on Climate Change [Core Writing Team], Pachauri RK, Reisinger A (eds). IPCC: Geneva; 104.

IPCC. 2013. Climate Change 2013: The Physical Science Basis. Contribution of Working Group I to the Fifth Assessment Report of the Intergovernmental Panel on Climate Change [Stocker, T.F., D. Qin, G.-K. Plattner, M. Tignor, S.K. Allen, J. Boschung, A. Nauels, Y. Xia, V. Bex and P.M. Midgley (eds.)]. Cambridge University Press, 
Cambridge, United Kingdom and New York, NY, USA, 1535 pp, doi:10.1017/CBO9781107415324.

Kapos V, J Rhind, M Edwards, and MF Price. 2000. Developing a map of the world's mountain forests, in Forests in Sustainable Mountain Development: A State-ofKnowledge Report for 2000, edited by M. F. Price, and N. Butt, CAB Int., Wallingford, U. K.

Keller F, Goyette S, Beniston M. 2005. Sensitivity analysis of snow cover to climate change scenarios and their impact on plant habitats in alpine terrain. Clim Change;72:299319.

Kim J, Sanjay J, Mattmann C, Boustani M, Ramarao MV, Krishnan R. and Waliser D. 2015. Uncertainties in estimating spatial and interannual variations in precipitation climatology in the India-Tibet region from multiple gridded precipitation datasets. International Journal of Climatology 35(15):4557-4573.

Knowles N, Dettinger MD, and Cayan DR. 2006. Trends in Snowfall versus Rainfall in the Western United States. Journal of Climate 19(18):4545-4559.

Korner, C. 1998. A reassessment of high elevation treeline positions and their explanation. Oecologia 115:445-459.

Kumari M, Basistha A, Bakimchandra O, and Singh CK. 2016. Comparison of Spatial Interpolation Methods for Mapping Rainfall in Indian Himalayas of Uttarakhand Region. Cham: Springer International Publishing. p 159-168.

Lenoir J, Graae BJ, Aarrestad PA, Alsos IG, Armbruster WS, Austrheim G, Bergendorff C, Birks HJB, Bra ${ }^{\circ}$ then KA, Brunet J, Bruun HH, Dahlberg CJ, Decocq G, Diekmann M, Dynesius M, et al. 2013. Local temperatures inferred from plant communities suggest strong spatial buffering of climate warming across Northern Europe. Global Change Biology 19:1470-1481.

López-Moreno JI, Vicente-Serrano SM, Morán-Tejeda E, Lorenzo-Lacruz J, Kenawy A, and Beniston M. 2011a. Effects of the North Atlantic Oscillation (NAO) on combined temperature and precipitation winter modes in the Mediterranean mountains: Observed relationships and projections for the 21st century. Global and Planetary Change 77(1):62-76.

López-Moreno JI, Goyette S, Vicente-Serrano SM, and Beniston M. 2011b. Effects of climate change on the intensity and frequency of heavy snowfall events in the Pyrenees. Climatic Change 105(3):489-508.

López-Moreno JI, Revuelto J, Gilaberte M, Morán-Tejeda E, Pons M, Jover E, Esteban P, García C, Pomeroy JW. 2013. The effect of slope aspect on the response of snowpack to climate warming in the Pyrenees. Theoretical and Applied Climatology 117: 1-13.

Lorenzo-Lacruz J, Vicente-Serrano SM, López-Moreno JI, Morán-Tejeda E, and Zabalza J. 2012. Recent trends in Iberian streamflows (1945-2005). Journal of Hydrology 414415:463-475.

Lundquist JD, and Cayan DR. 2007. Surface temperature patterns in complex terrain: Daily variations and long-term change in the central Sierra Nevada, California. Journal of Geophysical Research D: Atmospheres 112(11).

Masson D. and Frei C. 2014. Spatial analysis of precipitation in a high-mountain region: exploring methods with multi-scale topographic predictors and circulation types, Hydrol. Earth Syst. Sci., 18, 4543-4563.

Maraun D, F. Wetterhall, A. M. Ireson, R. E. Chandler, E. J. Kendon, M. Widmann, S. Brienen, H. W. Rust, T. Sauter, M. Themeßl, V. K. C. Venema, K. P. Chun, C. M. Goodess, R. G. Jones, C. Onof, M. Vrac, I. Thiele- Eich. 2010. Precipitation downscaling under climate change: Recent developments to bridge the gap between dynamical models and the end user. Reviews of Geophysics 48(3). 
Marks D, Winstral A, Reba M, Pomeroy J, and Kumar M. 2013. An evaluation of methods for determining during-storm precipitation phase and the rain/snow transition elevation at the surface in a mountain basin. Advances in Water Resources 55:98-110.

Matthews JL, Mannshardt E, Gremaud P. 2013. Uncertainty Quantification for Climate Observations. Bull Am Meteorol Soc 94: ES21-ES25.

Maussion F, Scherer D, Mölg T, Collier E, Curio J, and Finkelnburg R. 2014. Precipitation Seasonality and Variability over the Tibetan Plateau as Resolved by the High Asia Reanalysis. Journal of Climate 27(5):1910-1927.

Millar CI, Westfall RD, Delany DL. 2014. Thermal regimes and snowpack relations of periglacial talus slopes, Sierra Nevada, California, USA. Arctic, Antarctic, and Alpine Research 46:483-504.

Minder JR, PW Mote, and JD Lundquist. 2010. Surface temperature lapse rates over complex terrain: Lessons from the Cascade Mountains. Journal of Geophysical Research: Atmospheres 115(D14).

Mitchell TD, and Jones PD. 2005. An improved method of constructing a database of monthly climate observations and associated high-resolution grids. International Journal of Climatology 25(6):693-712.

Morrison C, and Pickering CM. 2013. Perceptions of climate change impacts, adaptation and limits to adaption in the Australian Alps: the ski-tourism industry and key stakeholders. Journal of Sustainable Tourism 21(2):173-191.

Návar J, and Lizárraga-Mendiola L. 2013. Hydro-climatic variability and forest fires in Mexico's northern temperate forests. Geofísica Internacional 52(1):5-20.

Nogués-Bravo D, Araújo MB, Errea MP, and Martínez-Rica JP. 2007. Exposure of global mountain systems to climate warming during the 21st Century. Global Environmental Change 17(3):420-428.

Palazzi E, J. von Hardenberg, and A. Provenzale. 2013. Precipitation in the Hindu-Kush Karakoram Himalaya: Observations and future scenarios. Journal of Geophysical Research: Atmospheres 118(1):85-100.

Pankaj K, Sven K, Christopher M, Kevin S, Holger F, Markus S, and Daniela J. 2015. Response of Karakoram-Himalayan glaciers to climate variability and climatic change: A regional climate model assessment. Geophysical Research Letters 42(6):1818-1825.

Paul F. 2011. Melting glaciers and icecaps. Nat Geosci.;4(2):71-72.

Pellicciotti F, Ragettli S, Carenzo M, and McPhee J. 2014. Changes of glaciers in the Andes of Chile and priorities for future work. Science of The Total Environment 493:11971210.

Pepin NC, and Lundquist JD. 2008. Temperature trends at high elevations: Patterns across the globe. Geophysical Research Letters 35(14).

Peterson, D. W. and Peterson, D. L. (2001), Mountain Hemlock growth responds to climatic variability at annual and decadal time scales. Ecology, 82: 3330-3345

Pittock AB. 1980. Patterns of Climatic Variation in Argentina and Chile-I Precipitation, 1931-60. Monthly Weather Review 108(9):1347-1361.

Rands MRW, Adams WM, Bennun L, Butchart SHM, Clements A, Coomes D, Entwistle A, Hodge I, Kapos V, Scharlemann JPW et al. . 2010. Biodiversity Conservation: Challenges Beyond 2010. Science 329(5997):1298-1303.

Raut BA, Jakob C, and Reeder MJ. 2014. Rainfall Changes over Southwestern Australia and Their Relationship to the Southern Annular Mode and ENSO. Journal of Climate 27(15):5801-5814.

Ray DK, Gerber JS, MacDonald GK, and West PC. 2015. Climate variation explains a third of global crop yield variability. Nature Communications 6:5989. 
Remesan R, and Holman IP. 2015. Effect of baseline meteorological data selection on hydrological modelling of climate change scenarios. Journal of Hydrology 528:631642.

Rohrer M, Salzmann N, Stoffel M, and Kulkarni AV. 2013. Missing (in-situ) snow cover data hampers climate change and runoff studies in the Greater Himalayas. Science of The Total Environment 468-469:S60-S70.

Saji NH, Goswami BN, Vinayachandran PN, and Yamagata T. 1999. A dipole mode in the tropical Indian Ocean. Nature 401:360.

Serreze MC, Walsh JE, Chapin FS III, Osterkamp T, Dyurgerov D, Romanovsky V, Oechel WC, Morison J, Zhang T, Barry RG. 2000. Observational evidence of recent change in the northern high-latitude environment. Climatic Change 46(1-2): 159-207.

Sexstone GA, Fassnacht SR, López-Moreno JI and Hiemstra CA. 2016. Subgrid snow depth coefficient of variation within complex mountainous terrain, The Cryosphere Discuss., https://doi.org/10.5194/tc-2016-188, in review.

Shamir E, Rimmer A, and Georgakakos K. 2016. The Use of an Orographic Precipitation Model to Assess the Precipitation Spatial Distribution in Lake Kinneret Watershed. Water 8(12):591.

Shen M, Piao S, Cong N, Zhang G, Jassens IA. 2015. Precipitation impacts on vegetation spring phenology on the Tibetan Plateau. Global Change Biology, 21, 554 36473656.

Siler N. and G. Roe. 2014. How will orographic precipitation respond to surface warming? An idealized thermodynamic perspective, Geophys. Res. Lett., 41, 2606-2613.

Spinoni J, Lakatos M, Szentimrey T, Bihari Z, Szalai S, Vogt J, Antofie T. 2015. Heat and cold waves trends in the Carpathian region from 1961 to 2010 . Int. J. Climatol. 35(14): 4197-4209.

Smith D. and Vivekananda J. 2012. Climate Change, Conflict, and Fragility: Getting the Institutions Right. In J. Scheffran, M. Brzoska, H. G. Brauch, P. M. Link \& J. Schilling (Eds.), Climate Change, Human Security and Violent Conflict: Challenges for Societal Stability (pp. 77-90). Berlin, Heidelberg: Springer.

Stahl K, Moore RD, Floyer JA, Asplin MG, and McKendry IG. 2006. Comparison of approaches for spatial interpolation of daily air temperature in a large region with complex topography and highly variable station density. Agricultural and Forest Meteorology 139(3):224-236.

Strachan S, Kelsey EP, Brown RF, Dascalu S, Harris F, Kent G, Lyles B, McCurdy G, Slater D, and Smith K. 2016. Filling the Data Gaps in Mountain Climate Observatories Through Advanced Technology, Refined Instrument Siting, and a Focus on Gradients. Mountain Research and Development 36(4):518-527.

Stewart IT. 2009. Changes in snowpack and snowmelt runoff for key mountain regions. Hydrological Processes 23(1):78-94.

Tanarhte M, P. Hadjinicolaou and J. Lelieveld. 2012. Intercomparison of temperature and precipitation data sets based on observations in the Mediterranean and the Middle East. Journal of Geophysical Research: Atmospheres 117(D12).

Trenberth KE, and Hurrell JW. 1994. Decadal atmosphere-ocean variations in the Pacific. Climate Dynamics 9(6):303-319.

Trenberth KE and Shea DJ. 2005. Relationships between precipitation and surface temperature. Geophys Res Lett 32: L14703. doi:10.1029/2005GL022760.

Trenberth KE, Jones PD, Ambenje P, Bojariu R, Easterling D, Klein Tank A, Parker D, Rahimzadeh F, Renwick JA, Rusticucci M, Soden B, Zhai P, 2007. Observations: Surface and Atmospheric Climate Change. In Climate Change 2007: The Physical Science Basis, Contribution of Working Group I to the Fourth Assessment Report of 
the Intergovernmental Panel on Climate Change, Solomon S, Qin D, Manning M, Chen Z, Marquis M, Averyt KB, Tignor M, Miller HL (eds). Cambridge University Press: Cambridge, New York.

UN. 1992. Earth Summit: Agenda 21. The United Nations Programme of Action From Rio.

The final text of agreements negotiated by governments at the United Nations Conference on Environment and Development (UNCED), 3-14 June 1992, Rio de Janeiro, Brazil; 294 pp.

Vicente-Serrano SM, Aguilar E, Martínez R, Martín-Hernández N, Azorin-Molina C, Sanchez-Lorenzo A, El Kenawy A, Tomás-Burguera M, Moran-Tejeda E, LópezMoreno JI et al. . 2017. The complex influence of ENSO on droughts in Ecuador. Climate Dynamics 48(1):405-427.

Vinnikov KY, Groisman PY, and Lugina KM. 1990. Empirical Data on Contemporary Global Climate Changes (Temperature and Precipitation). Journal of Climate 3(6):662-677.

Yin H, Donat MG, Alexander LV and Sun Y. 2015. Multi- dataset comparison of gridded observed temperature and precipitation extremes over China. Int. J. Climatol., 35: 2809-2827. doi:10.1002/joc.4174.

Table 1: A list of the circulation indices used in this study.

\begin{tabular}{lll}
\hline $\begin{array}{l}\text { Index } \\
\text { abbreviation }\end{array}$ & Description & Reference \\
\hline AMM & Atlantic Meridional Mode & Chiang \& Vimont (2004) \\
AMO & Atlantic Multidecadal Oscillation & Enfield et al. (2001) \\
AO & Arctic Oscillation & Higgins et al. (2001) \\
BOMBAY & Bombay SLP anomaly pattern & Berhane et al. (2014) \\
EA & East Atlantic & www.cpc.noaa.gov/data/teledoc/telecontents.shtml \\
& Eastern Atlantic-Western Russian & \\
EAWR & pattern & www.cpc.ncep.noaa.gov/data/teledoc/eawruss.shtml \\
IOD & Indian Ocean Dipole & Saji et al. (1999) \\
MEI & Multivariate ENSO Index & Wolter et al. (1998) \\
MOI & Mediterranean Oscillation index & Palutikof et al. (1996) \\
NAO & North Atlantic Oscillation & Jones et al. (1997) \\
NP & Northern Pacific & Trenberth and Hurrell (1994). \\
PDO & Pacific Decadal Oscillation & Mantua et al. (1997) \\
SCA & Scandinavian pattern & www.cpc.noaa.gov/data/teledoc/telecontents.shtml \\
SOI & Southern Oscillation index & NOAA CPC \\
TPI & Trans Polar Index & Pittock (1980) \\
& Western Mediterranean Oscillation & \\
WEMOI & index & Martin-Vide \& Lopez-Bustins (2006) \\
WP & Western Pacific & Barnston and Livezey (1987) \\
\hline
\end{tabular}


Table 2: Contingency tables summarizing the association between the different trend categories (i.e. statistically significant positive [+], statistically significant negative [-], statistically insignificant positive $[\mathrm{N}+]$, statistically insignificant negative $[\mathrm{N}-]$ ) of air temperature and annual total precipitation. The statistical significance was assessed at the $95 \%$ level $(p<0.05)$. Numbers represent the percentage of grids corresponding to each category.

\begin{tabular}{|c|c|c|c|c|c|}
\hline & & \multicolumn{3}{|c|}{ Alps } & \\
\hline \multirow{8}{*}{$\begin{array}{c}\text { Tem } \\
\text { p. }\end{array}$} & & \multicolumn{4}{|c|}{ Precip. } \\
\hline & & + & - & $\mathrm{N}+$ & $\mathrm{N}-$ \\
\hline & + & 2.2 & 0. & 32. & 65. \\
\hline & & & 0 & 6 & 2 \\
\hline & & 0.0 & 0 & 0.0 & 0.0 \\
\hline & $\mathrm{N}$ & & 0. & & \\
\hline & + & 0.0 & 0 & 0.0 & 0.0 \\
\hline & $\mathrm{N}-$ & 0.0 & $\begin{array}{c}0 . \\
0\end{array}$ & 0.0 & 0.0 \\
\hline
\end{tabular}

\begin{tabular}{|c|c|c|c|c|c|}
\hline & & \multicolumn{4}{|c|}{ Anatolia } \\
\hline \multirow{8}{*}{$\begin{array}{c}\text { Tem } \\
\text { p. }\end{array}$} & & \multicolumn{4}{|c|}{ Precip. } \\
\hline & & + & - & $\mathrm{N}+$ & N- \\
\hline & + & 10. & 0. & 19. & 39.8 \\
\hline & & 0 & 0 & 9 & \\
\hline & & 0.0 & 0 & 0.0 & 0.0 \\
\hline & $\mathrm{N}$ & & 0 . & 14. & \\
\hline & + & 4.0 & 0 & 4 & 5.0 \\
\hline & N- & 0.0 & $\begin{array}{c}0 . \\
0\end{array}$ & 1.0 & 6.0 \\
\hline
\end{tabular}

\begin{tabular}{|c|c|c|c|c|c|}
\hline & & \multicolumn{4}{|c|}{ Andes } \\
\hline \multirow{9}{*}{$\begin{array}{c}\text { Tem } \\
\text { p, }\end{array}$} & & \multicolumn{4}{|c|}{ Precip. } \\
\hline & & + & - & $\mathrm{N}+$ & $\mathrm{N}$ \\
\hline & + & \multirow[t]{2}{*}{4.5} & \multirow{3}{*}{$\begin{array}{c}0 . \\
0 \\
0 .\end{array}$} & \multirow{3}{*}{$\begin{array}{c}19 . \\
7\end{array}$} & \\
\hline & & & & & \\
\hline & & \multirow{2}{*}{0.0} & & & 00 \\
\hline & $\mathrm{N}$ & & 0. & 0.0 & \\
\hline & + & \multirow[t]{2}{*}{1.6} & 0 & 7.5 & 3 \\
\hline & & & 0. & 13. & 13 \\
\hline & N- & 1.0 & 0 & 2 & 5 \\
\hline
\end{tabular}

\begin{tabular}{|c|c|c|c|c|c|}
\hline & & \multicolumn{4}{|c|}{ Applach } \\
\hline \multirow{9}{*}{$\begin{array}{c}\text { Tem } \\
\text { p. }\end{array}$} & & \multicolumn{4}{|c|}{ Precip. } \\
\hline & & + & - & $\mathrm{N}+$ & $\mathrm{N}-$ \\
\hline & + & 42. & 0. & 42. & 14. \\
\hline & & 2 & 0 & 6 & \\
\hline & & & 0. & & \\
\hline & $N$ & 0.0 & 0 & 0.0 & 0.0 \\
\hline & + & 04 & 0 & 08 & 0.0 \\
\hline & & & 0. & & \\
\hline & N- & 0.0 & 0 & 0.0 & 0.0 \\
\hline
\end{tabular}

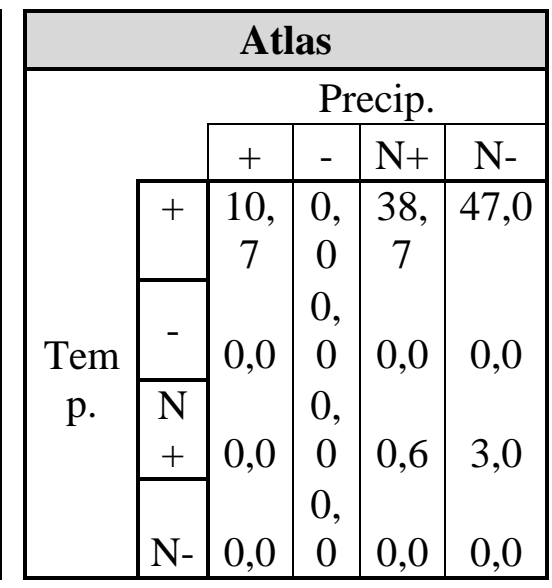

\begin{tabular}{|c|c|c|c|c|c|}
\hline \multicolumn{6}{|c|}{ Australian } \\
\hline \multirow{8}{*}{$\begin{array}{c}\text { Tem } \\
\text { p. }\end{array}$} & & \multicolumn{4}{|c|}{ Precip. } \\
\hline & & + & - & $\mathrm{N}+$ & $\mathrm{N}-$ \\
\hline & + & 0,0 & 0 , & 39 , & 52 , \\
\hline & & & 0 & & \\
\hline & - & 0,0 & 0 & 0,0 & 0,0 \\
\hline & $\mathrm{N}$ & & 0 , & & \\
\hline & + & 0,0 & 0 & 5,1 & 2,4 \\
\hline & N- & 0,0 & $\begin{array}{l}0, \\
0\end{array}$ & 0,0 & 0,0 \\
\hline
\end{tabular}

\begin{tabular}{|c|c|c|c|c|c|}
\hline & & \multicolumn{4}{|c|}{ Brooks } \\
\hline \multirow{9}{*}{$\begin{array}{c}\text { Tem } \\
\text { p. }\end{array}$} & & \multicolumn{4}{|c|}{ Precip. } \\
\hline & & + & - & $\mathrm{N}+$ & $\mathrm{N}-$ \\
\hline & + & 17 , & 0 & 17 & 65 \\
\hline & & 7 & 0 & 3 & 0 \\
\hline & & & 0 , & & \\
\hline & & 0,0 & 0 & 0,0 & 0,0 \\
\hline & $\mathrm{N}$ & & 0 , & & \\
\hline & + & 0,0 & 0 & 0,0 & 0,0 \\
\hline & N- & 0,0 & $\begin{array}{l}0, \\
0\end{array}$ & 0,0 & 0,0 \\
\hline
\end{tabular}

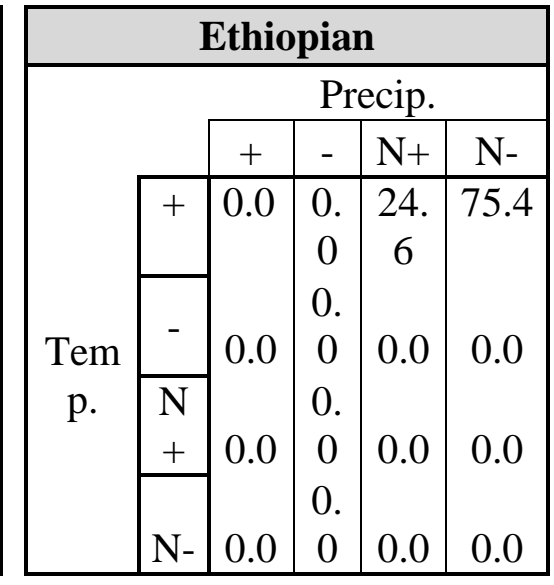

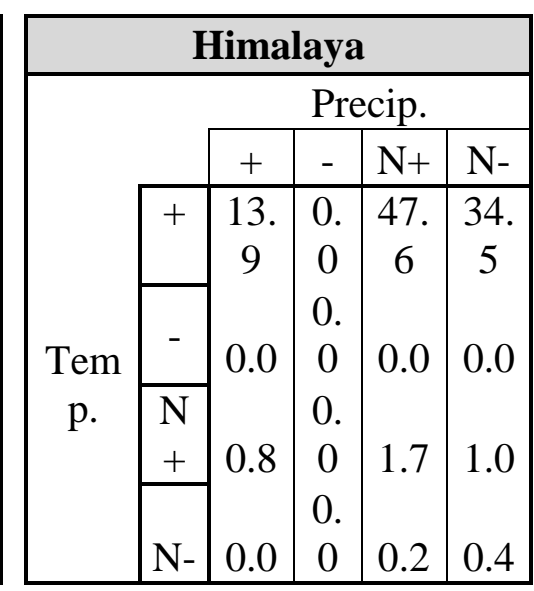



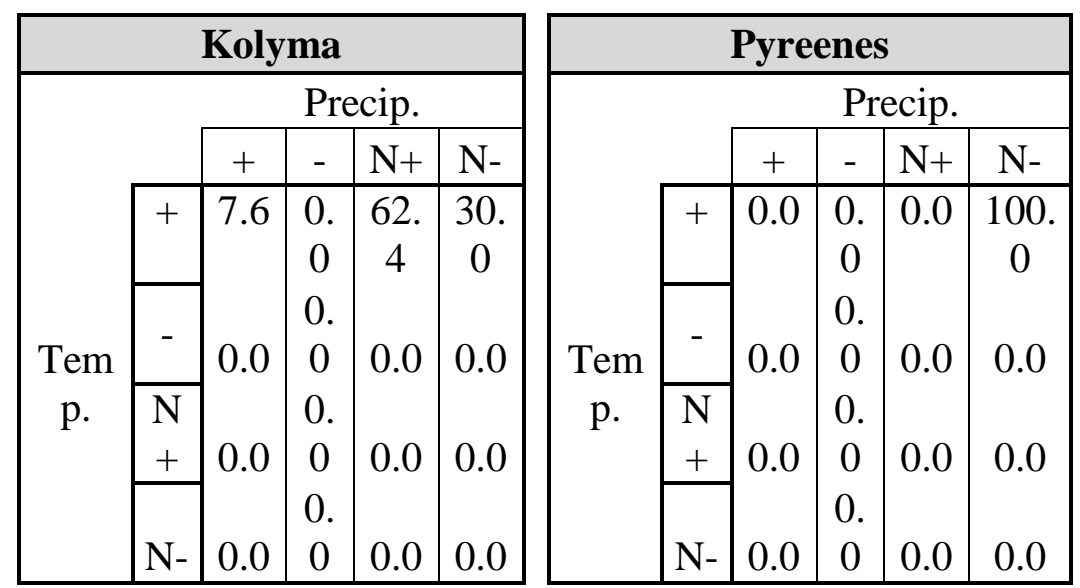

\begin{tabular}{|c|c|c|c|c|c|}
\hline & & \multicolumn{4}{|c|}{ Rocky } \\
\hline \multirow{8}{*}{$\begin{array}{c}\text { Tem } \\
\text { p. }\end{array}$} & & \multicolumn{4}{|c|}{ Precip. } \\
\hline & & + & - & $\mathrm{N}+$ & $\mathrm{N}-$ \\
\hline & + & 1.0 & 0 . & 33. & 45. \\
\hline & & & 0 & & \\
\hline & & 0.0 & 0 & 0.0 & 0.0 \\
\hline & $\mathrm{N}$ & & 0 . & & 12. \\
\hline & + & 0.6 & 0 & 3.9 & 2 \\
\hline & $\mathrm{N}-$ & 0.0 & $\begin{array}{c}0 . \\
0\end{array}$ & 2.2 & 1.1 \\
\hline
\end{tabular}

\begin{tabular}{|c|c|c|c|c|c|}
\hline \multicolumn{6}{|c|}{ Scandenavian } \\
\hline \multirow{9}{*}{$\begin{array}{c}\text { Tem } \\
\text { p. }\end{array}$} & & \multicolumn{4}{|c|}{ Precip. } \\
\hline & & + & - & $\mathrm{N}+$ & $\mathrm{N}-$ \\
\hline & + & 40. & 0. & 58. & 1.0 \\
\hline & & 1 & 0 & 4 & \\
\hline & - & & 0. & & \\
\hline & . & 0.0 & 0 & 0.0 & 0.0 \\
\hline & $\mathrm{N}$ & & 0. & & \\
\hline & + & 0.0 & 0 & 0.0 & 0.0 \\
\hline & N- & 0.0 & $\begin{array}{c}0 . \\
0\end{array}$ & 0.5 & 0.0 \\
\hline
\end{tabular}

Table 3: Changes in the surface area (\%/decade) exposed to the different four climate modes (cold-dry [CD], cold-wet [CW], warm-dry [WD] and warm-wet [WW]) from 1960 to 2013. Only statistically significant changes at the $95 \%$ level $(p<0.05)$ are given in bold.

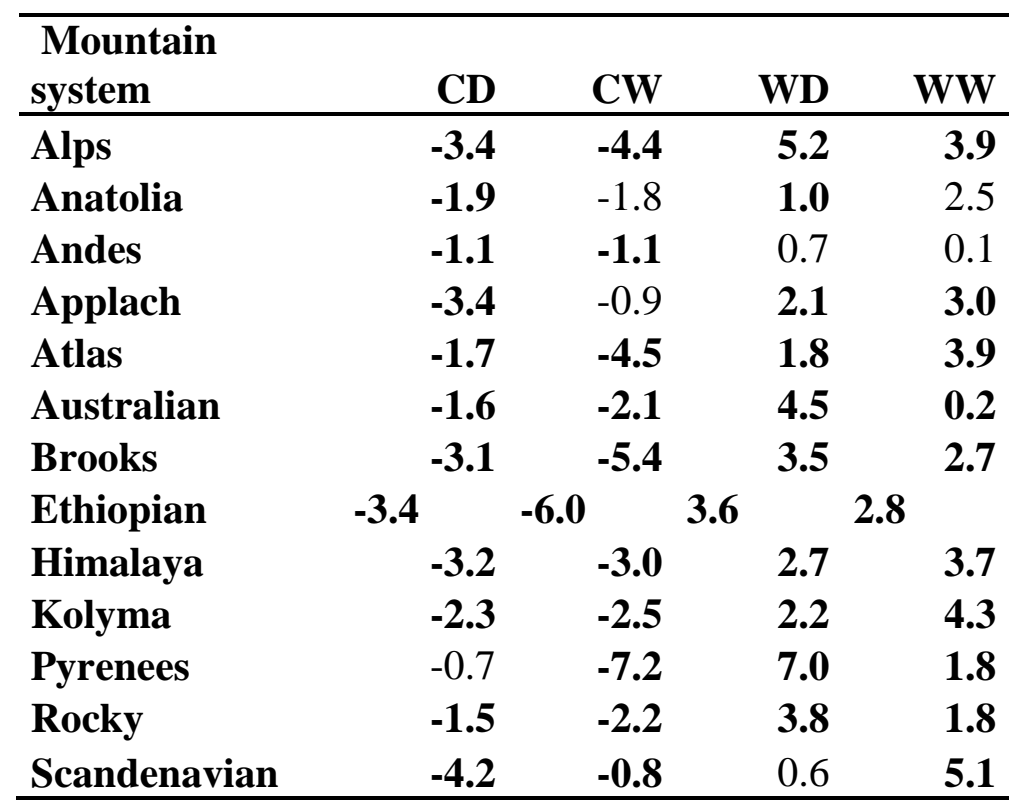


Table 4: The dominant phase of each circulation pattern, which is best-correlated with each climate mode and their impacted mountain region (s). The positive phase is labeled with $(+)$, while the negative phase is denoted with (-).

\begin{tabular}{|c|c|c|c|c|c|}
\hline \multirow[t]{2}{*}{ Index } & \multicolumn{4}{|c|}{ Climate mode } & \multirow[t]{2}{*}{ Mountain region } \\
\hline & CD & $\mathbf{C W}$ & WD & WW & \\
\hline AMM & - & - & + & + & Anatolia, Applach, Atlas, Himalaya \\
\hline AMO & - & - & + & + & Anatolia, Applach, Atlas, Brooks, Himalaya, Kolyma, Rocky \\
\hline Bombay & - & - & + & + & Australian \\
\hline MOI & + & + & + & + & Kolyma, Pyrenees, Rocky \\
\hline $\mathrm{AO}$ & - & - & + & + & Alps, Scandenavian \\
\hline $\mathrm{AO}$ & - & + & + & - & Ethiopian \\
\hline $\mathrm{AO}$ & + & + & - & - & Anatolia \\
\hline EA & - & - & + & + & Alps, Applach, Atlas, Himalaya, Rocky \\
\hline EA & + & - & - & - & Pyrenees \\
\hline MEI & - & - & + & + & Andes \\
\hline MEI & - & - & + & - & Ethiopian, Australian \\
\hline MEI & - & - & - & + & Brooks \\
\hline NAO & - & - & + & + & Alps, Scandenavian \\
\hline NAO & + & + & - & - & Anatolia \\
\hline PDO & - & - & + & + & Andes, Brooks \\
\hline PDO & - & - & + & - & Australian \\
\hline PDO & + & - & - & + & Rocky \\
\hline SCA & + & + & - & - & Atlas, Pyrenees \\
\hline SCA & - & + & - & - & Applach \\
\hline SCA & - & + & - & - & Pyrenees \\
\hline SCA & + & - & + & - & Scandenavian \\
\hline SOI & - & - & - & + & Kolyma \\
\hline SOI & + & + & - & - & Andes \\
\hline SOI & + & + & - & + & Australian \\
\hline WeMO & + & + & - & - & Alps, Pyrenees \\
\hline WeMO & + & - & - & - & Scandenavian \\
\hline WP & + & + & + & + & Himalaya \\
\hline WP & + & + & - & - & Kolyma \\
\hline TPI & - & - & + & - & Ethiopian \\
\hline TPI & - & - & + & + & Andes \\
\hline
\end{tabular}




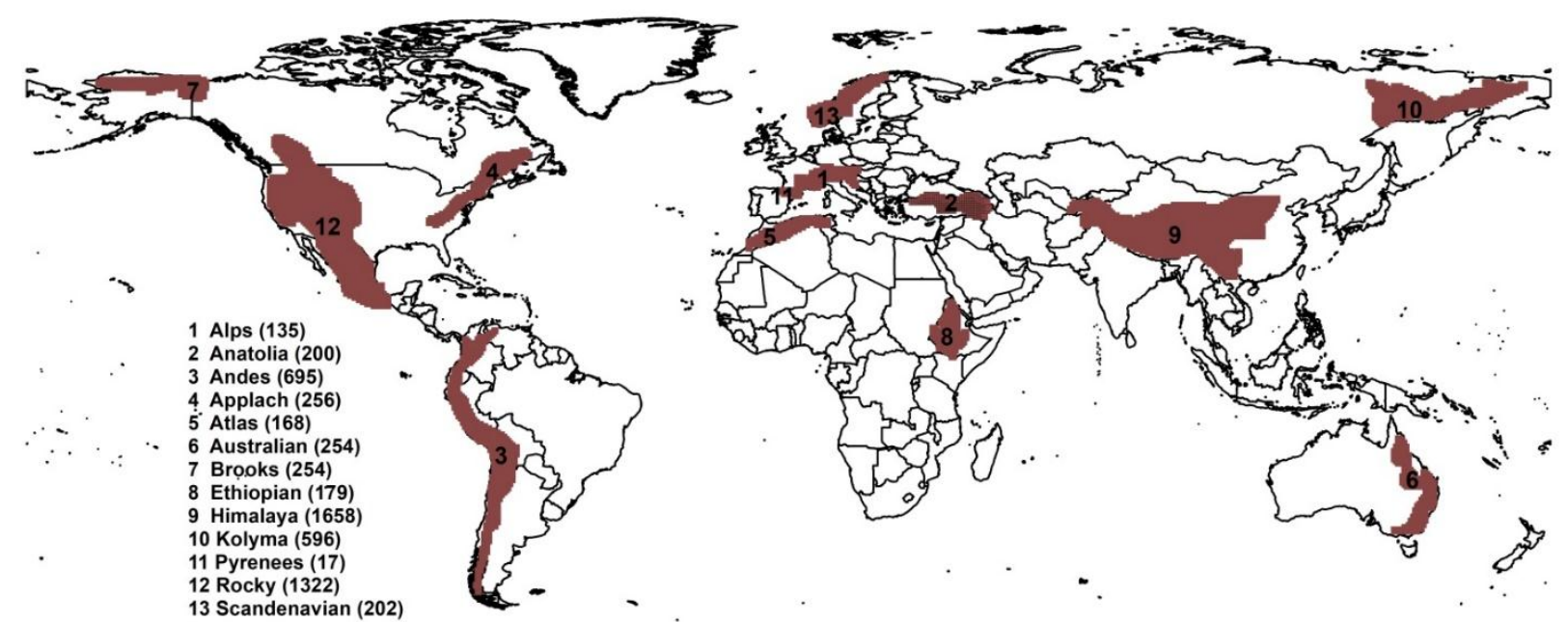

Figure 1: Location of the main mountain regions investigated in this study. Bracketed values in the legend represent the number of data grid points corresponding to each mountain system.
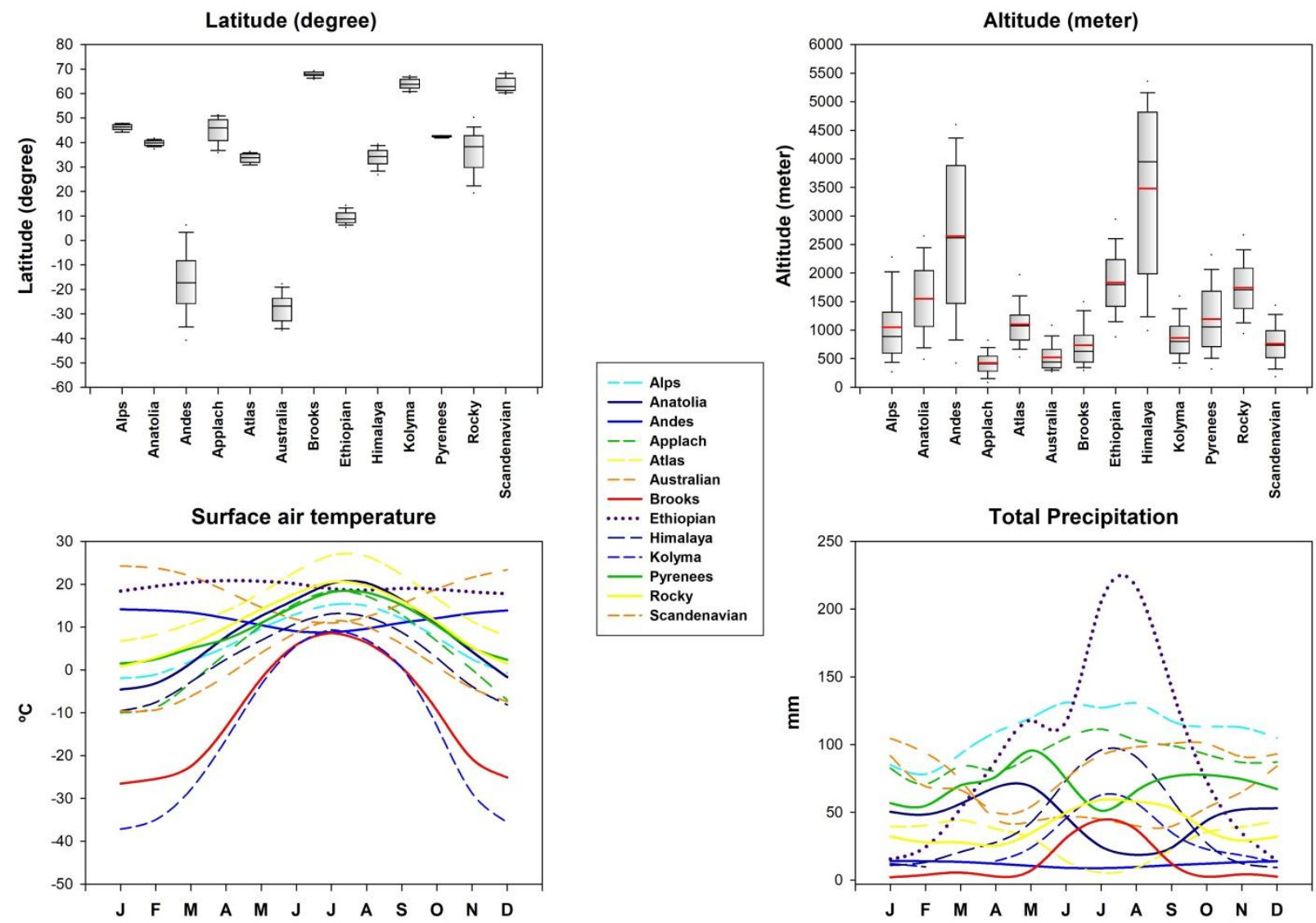

Figure 2: Differences amongst the 13 mountain systems in terms of latitudinal extension (upper left), altitude (upper right), and mean seasonal cycle of surface air temperature (lower left) and accumulated precipitation (lower right). Monthly climatological averages were computed for the period 1960-2013. 
Mean air temperature

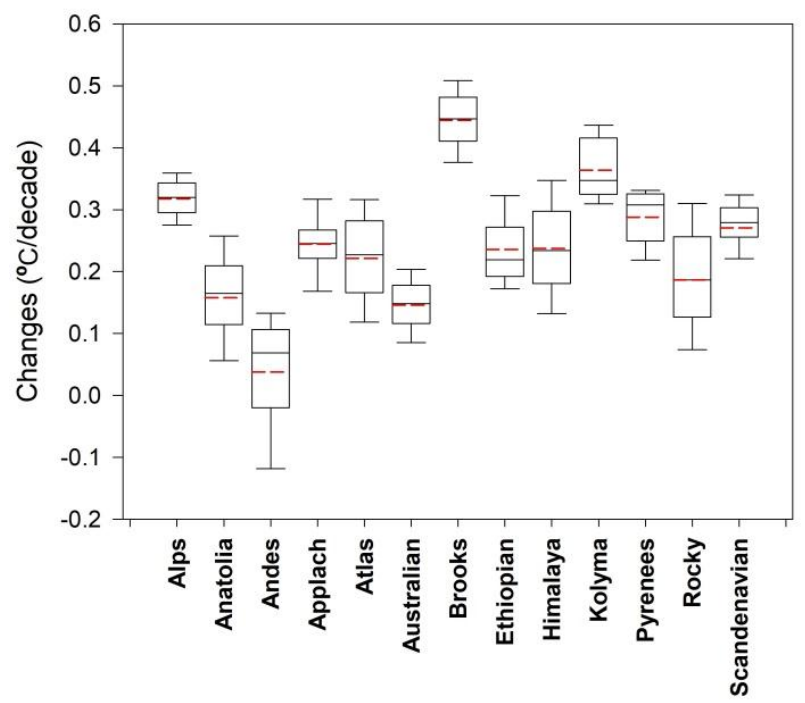

Total annual precipitation

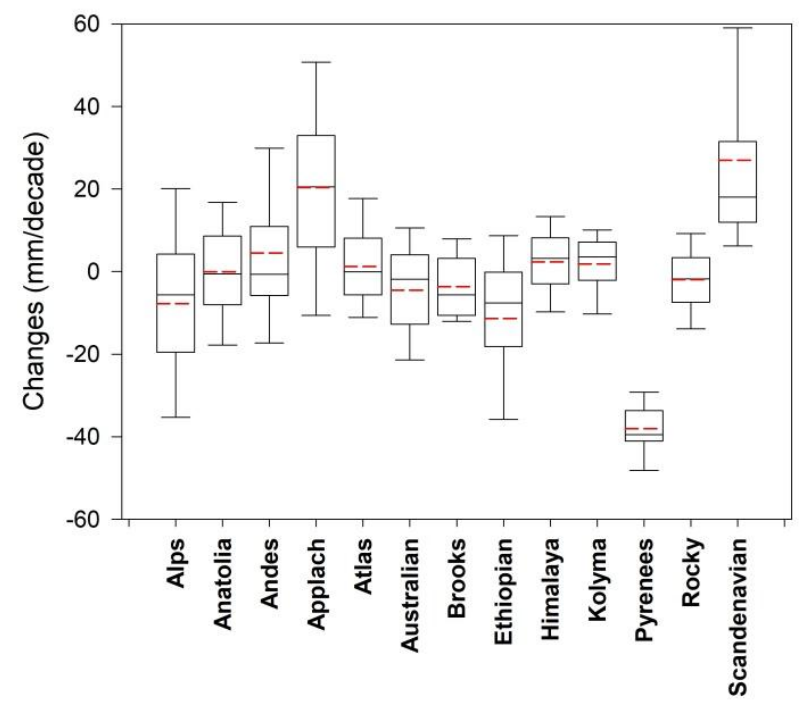

Figure 3: Amount of change in mean air temperature and total annual precipitation, calculated for the main mountain regions from 1960 to 2013. The central solid line indicates the median, whereas the central dashed red line refers to the mean. The whiskers represent the 10th and the 90th, while the 25 th and the $75^{\text {th }}$ are plotted as the vertical lines of the bounding boxes. 

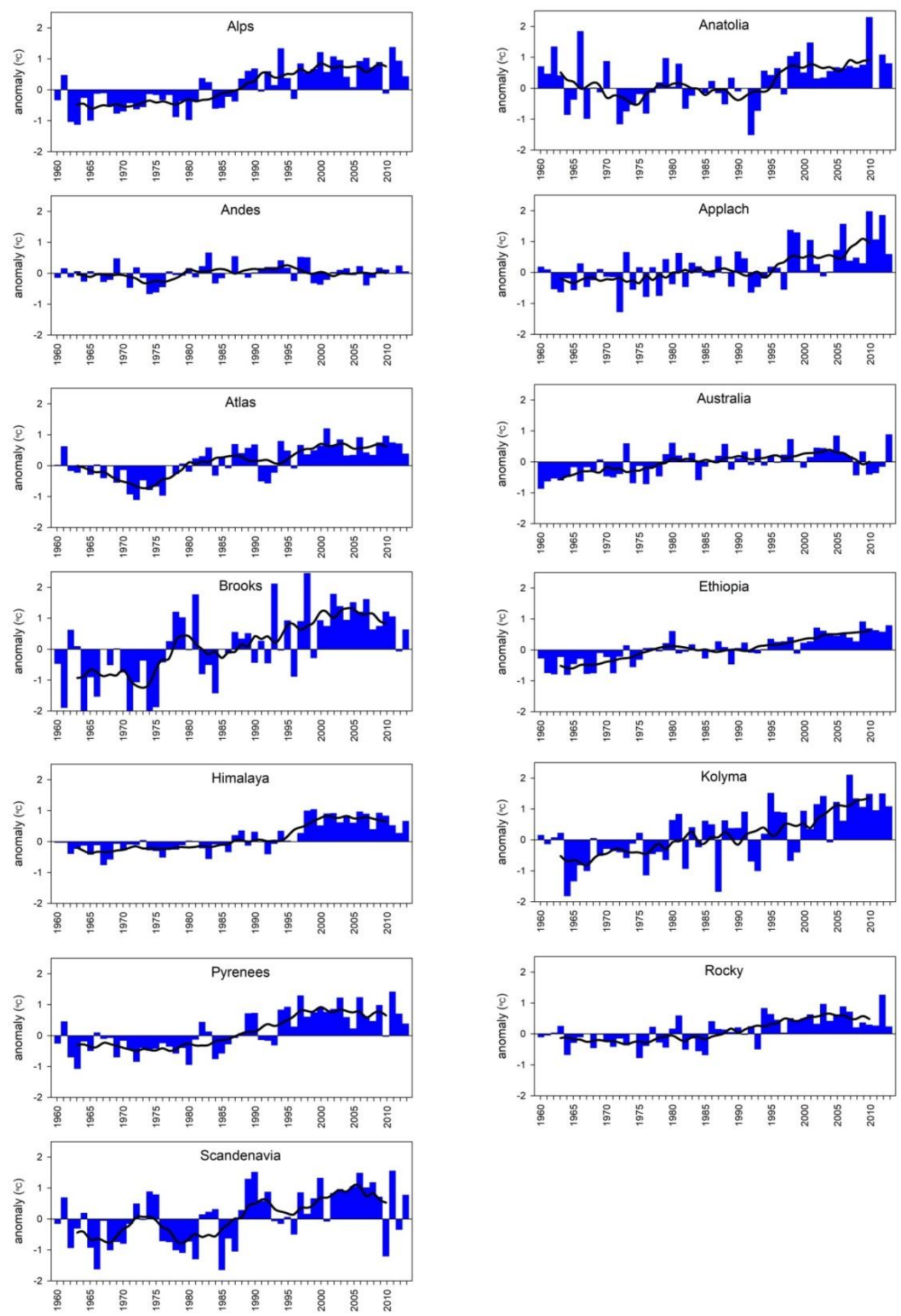

Figure 4: Anomalies of surface air mean temperature for the main mountain regions. Anomalies were calculated with respect to the base period 1970-2000. Black lines show a low Gaussian filter of 7 years. 

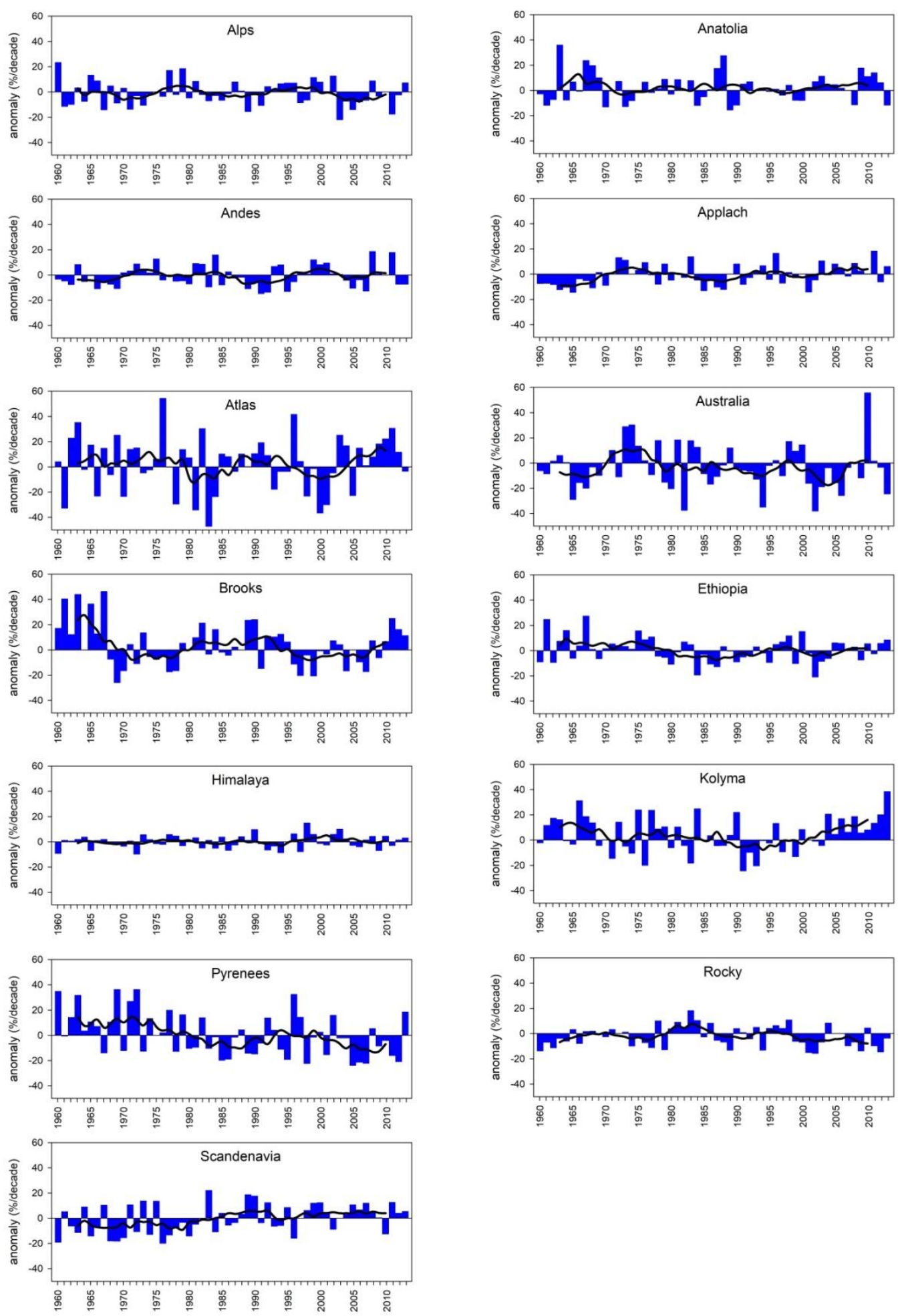

Figure 5: Anomalies of annual total precipitation (\%/decade) for the main mountain regions. Anomalies were calculated with respect to the base period 1970-2000. Black lines show a low Gaussian filter of 7 years. 

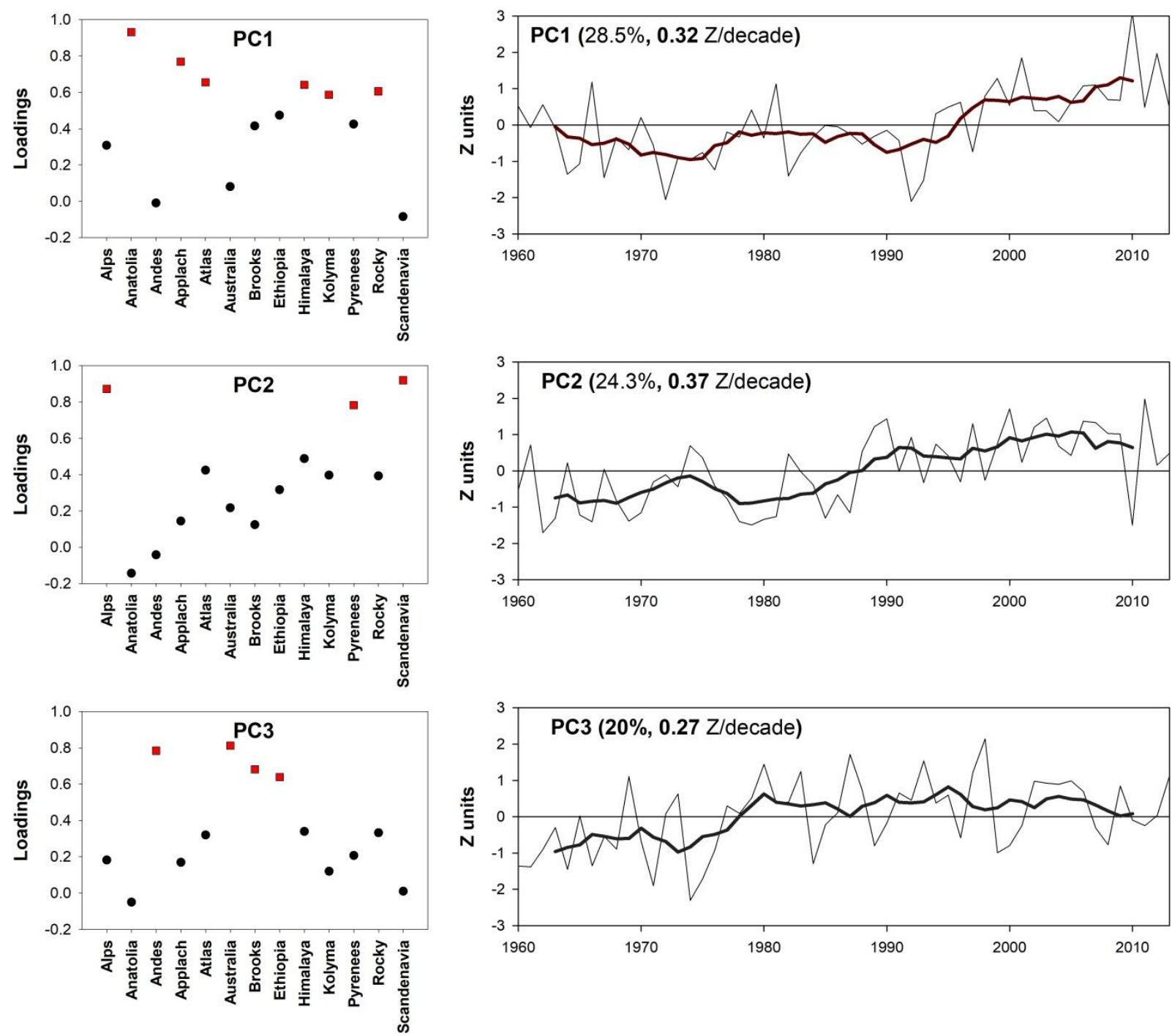

Figure 6: (Left) Factor loadings along the three main principal components of surface air temperature and (right) the time-series showing temporal variability corresponding to each component. For left panels, red squares refer to highest loadings along each component. For right panels, numbers between parentheses refer to the amount of variance explained by each factor (expressed in \%) and the magnitudes of trends (expressed in $Z$ units/decade), respectively. Only statistically significant trends at the $95 \%$ level $(p<0.05)$ are given in bold. Each time plot includes annual values (thin lines) and 7-yr running averages (bold lines). 

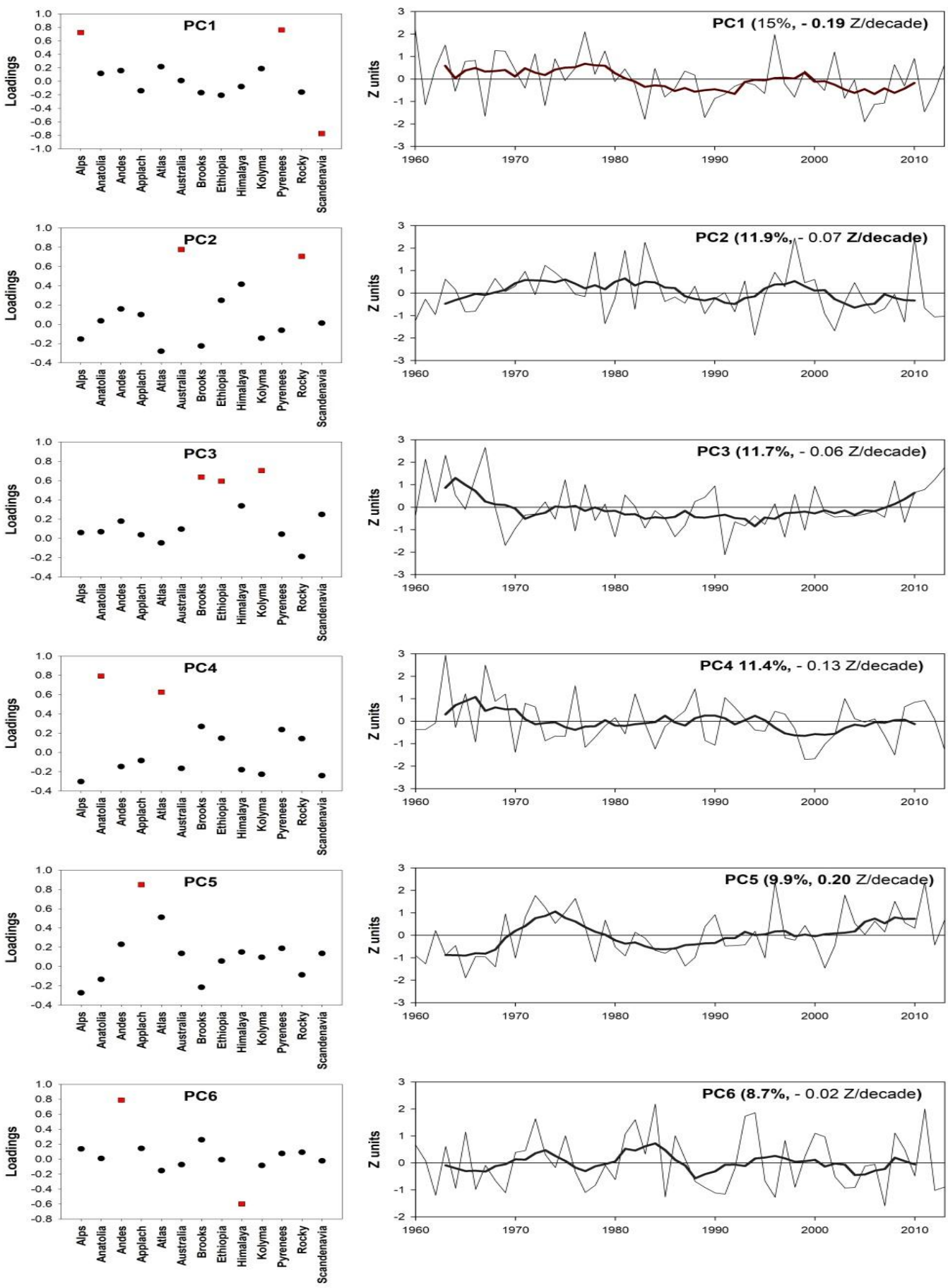

Figure 7: (Left) Factor loadings along the three main principal components of total annual precipitation and (right) the time-series showing temporal variability corresponding to each component. For left panels, red squares refer to highest loadings along each component. For right panels, numbers between parentheses refer to the amount of variance explained by each factor (expressed in \%) and the magnitudes of trends (expressed in $\mathrm{Z}$ units/decade), respectively. Only statistically significant trends at the $95 \%$ level $(p<0.05)$ are given in bold. Each time plot includes annual values (thin lines) and 7-yr running averages (bold lines). 

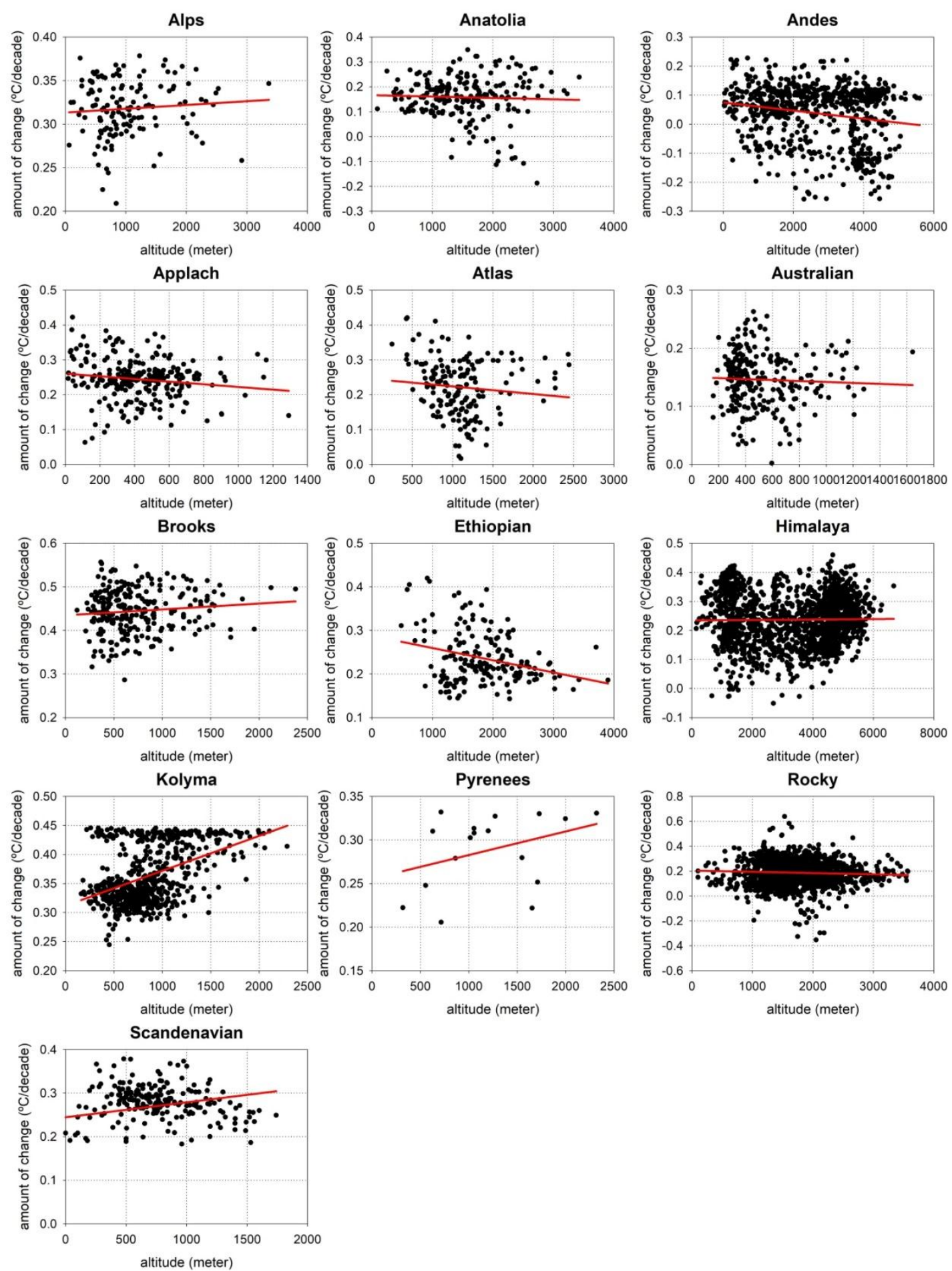

Figure 8: Scatter plots showing temperature trends as a function of the different altitudes. The fitted linear regression line for all data is shown in red. 

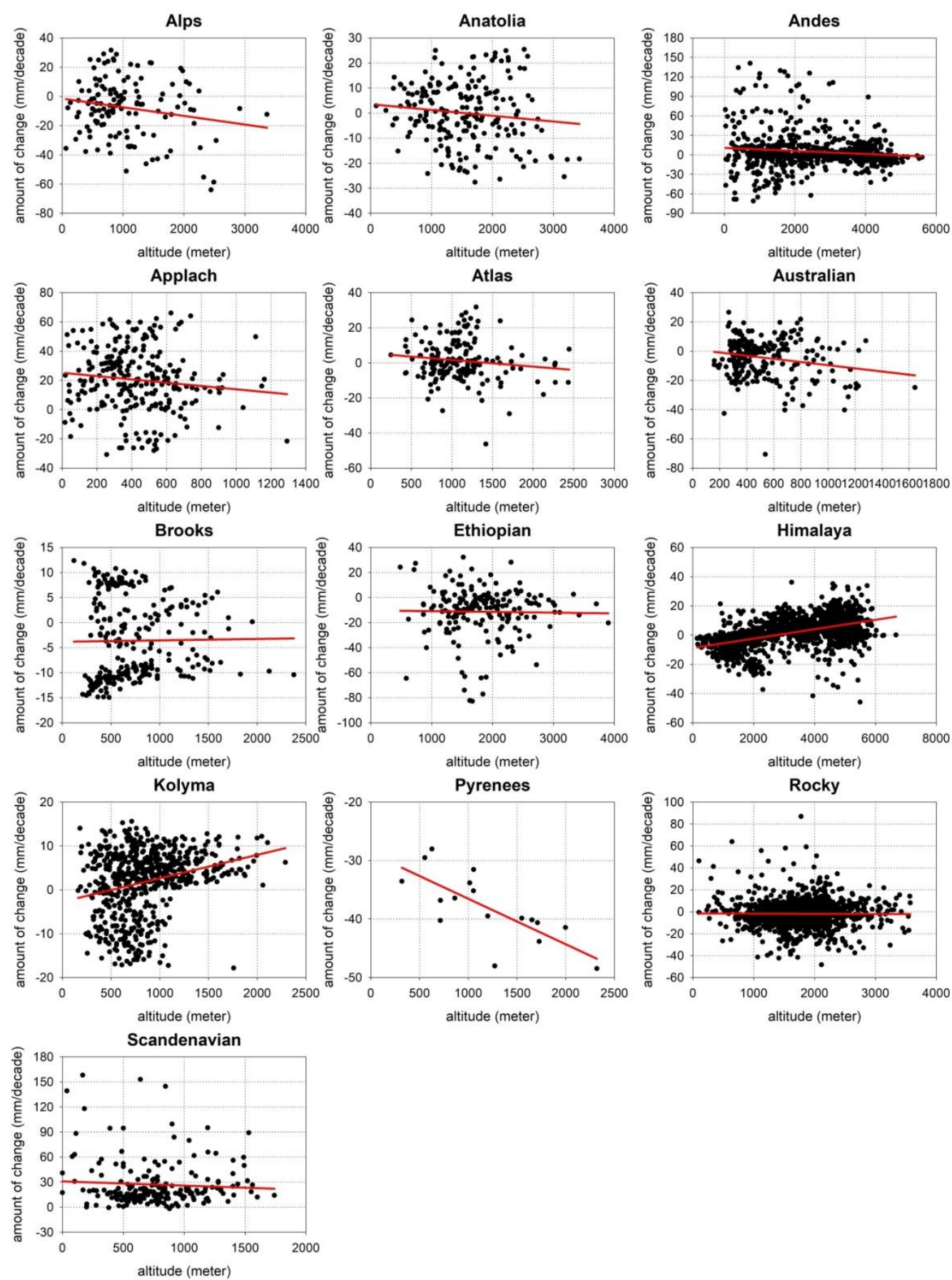

Figure 9: Scatter plots showing precipitation trends as a function of the different altitudes. The fitted linear regression line for all data is shown in red. 


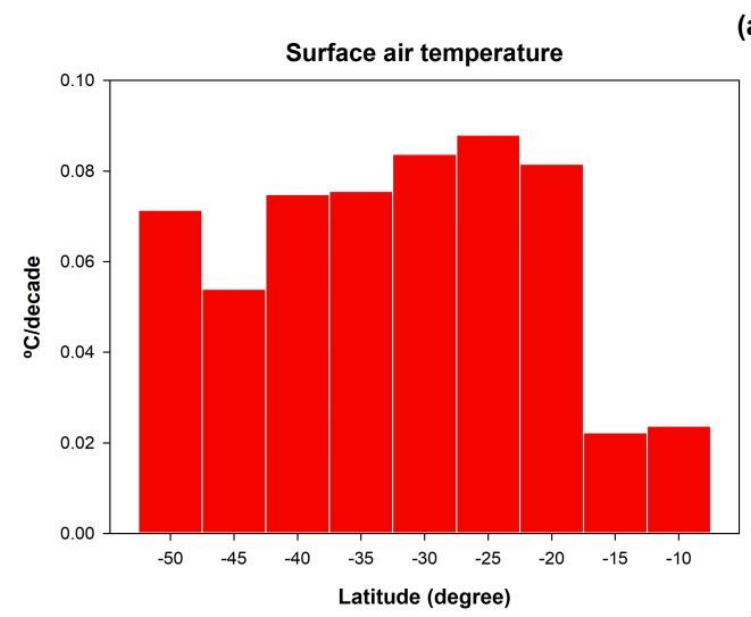

(a) Andes
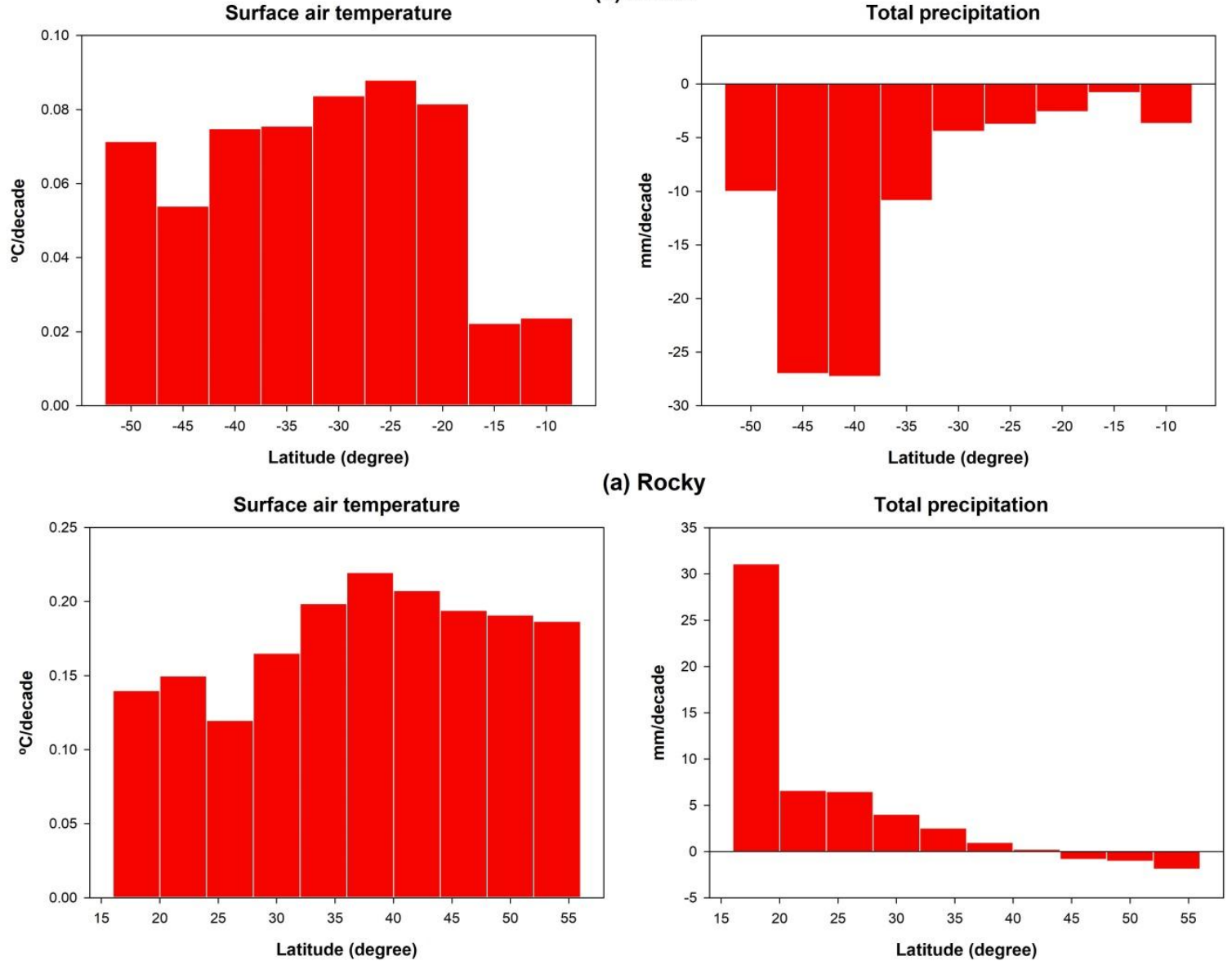

(a) Rocky

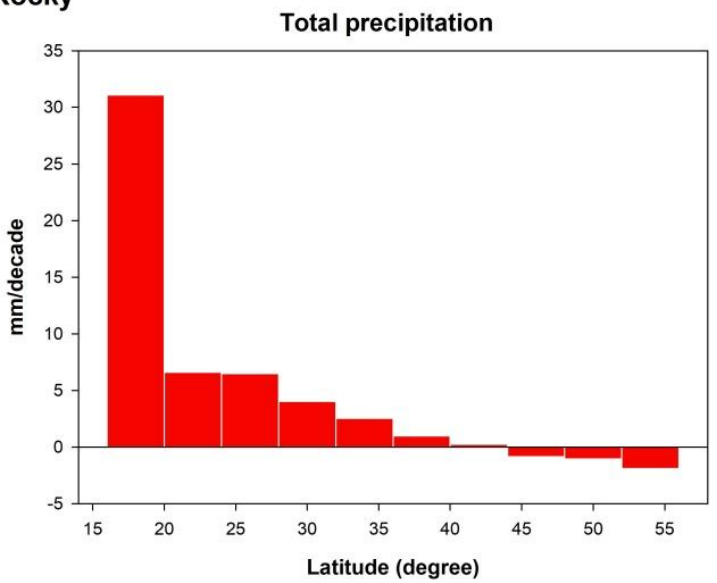

Figure 10: Amount of change in surface air temperature $\left({ }^{\circ} \mathrm{C} /\right.$ decade) and total precipitation ( $\mathrm{mm} /$ decade) as a function of latitude for the Andes and Rocky mountain systems. 

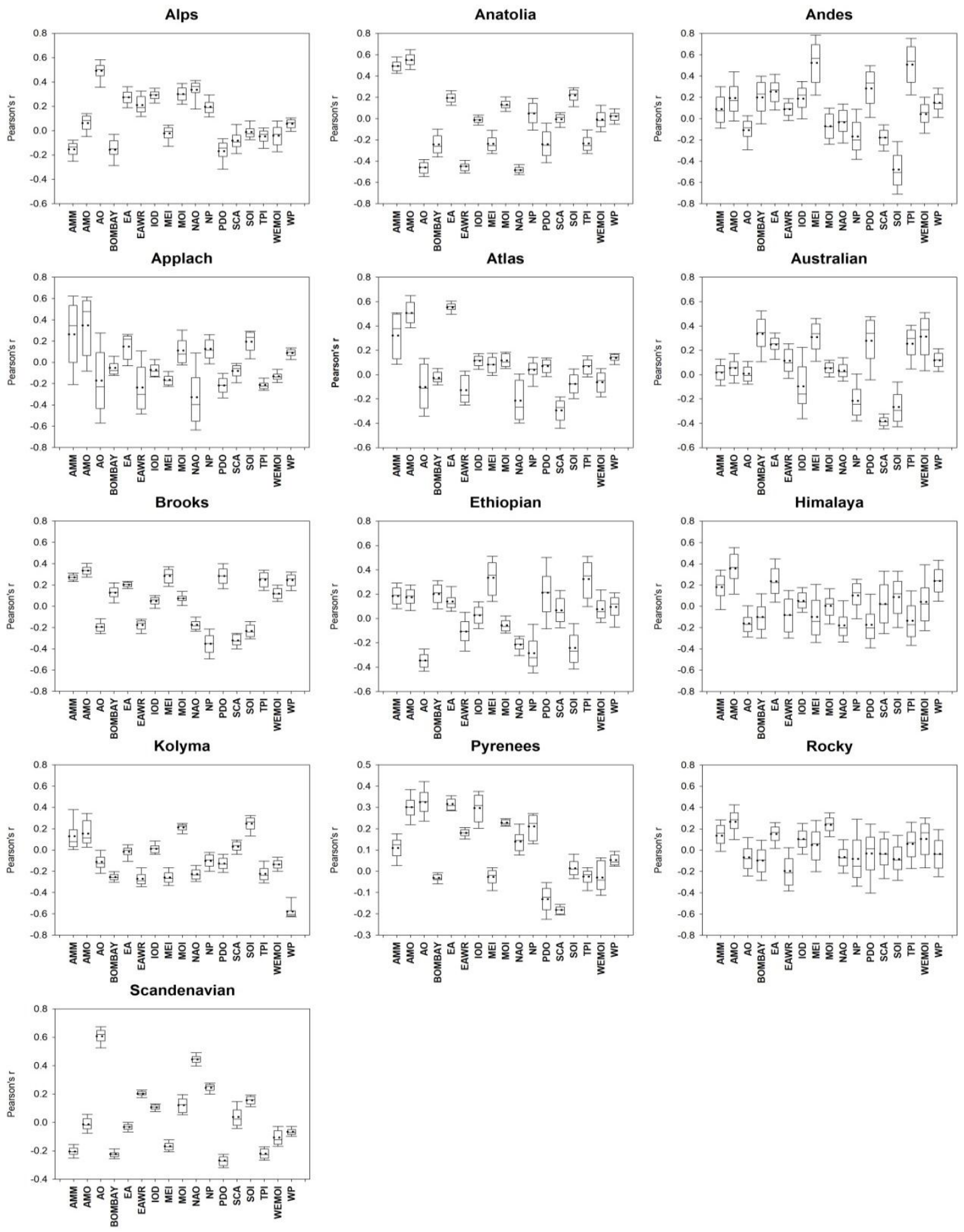

Figure 11: Boxplots summarizing Pearson's correlation coefficient calculated between the detrended series of annual surface air temperature and circulation indices for the period 1960-2013. Values higher (lower) than $0.26(-0.26)$ are statistically significant at $\mathbf{p}<0.05$. The central solid line indicates the median, whereas the central dashed line refers to the mean. The whiskers represent the 10th and the 90th, while the 25 th and the $75^{\text {th }}$ are plotted as the vertical lines of the bounding boxes. 

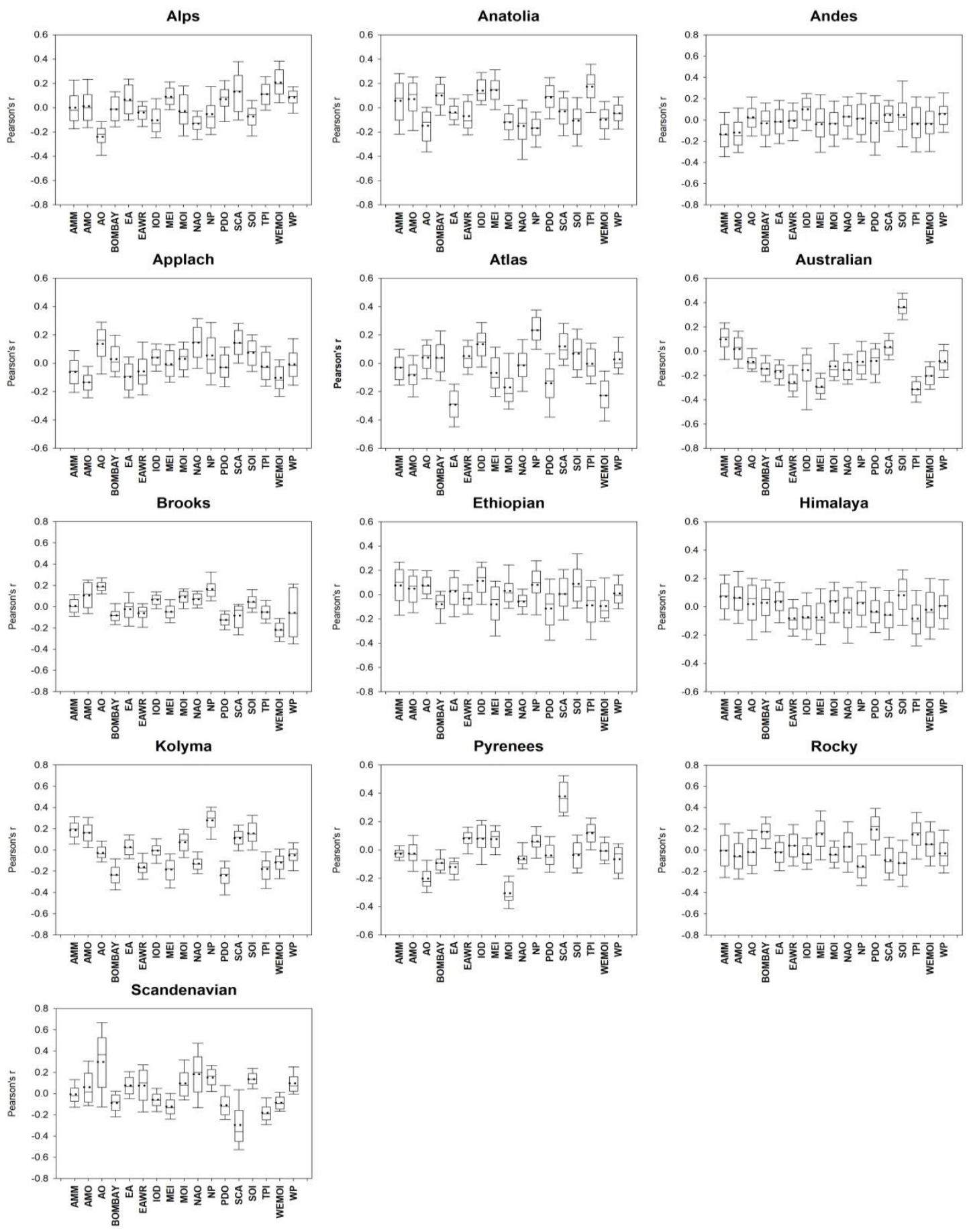

Figure 12: Boxplots summarizing Pearson's correlation coefficient calculated between the detrended series of annual rainfall totals and circulation indices for the period 19602013. Values higher (lower) than $0.26(-0.26)$ are statistically significant at $p<0.05$. The central solid line indicates the median, whereas the central dashed line refers to the mean. The whiskers represent the 10 th and the 90th, while the 25 th and the $75^{\text {th }}$ are plotted as the vertical lines of the bounding boxes. 

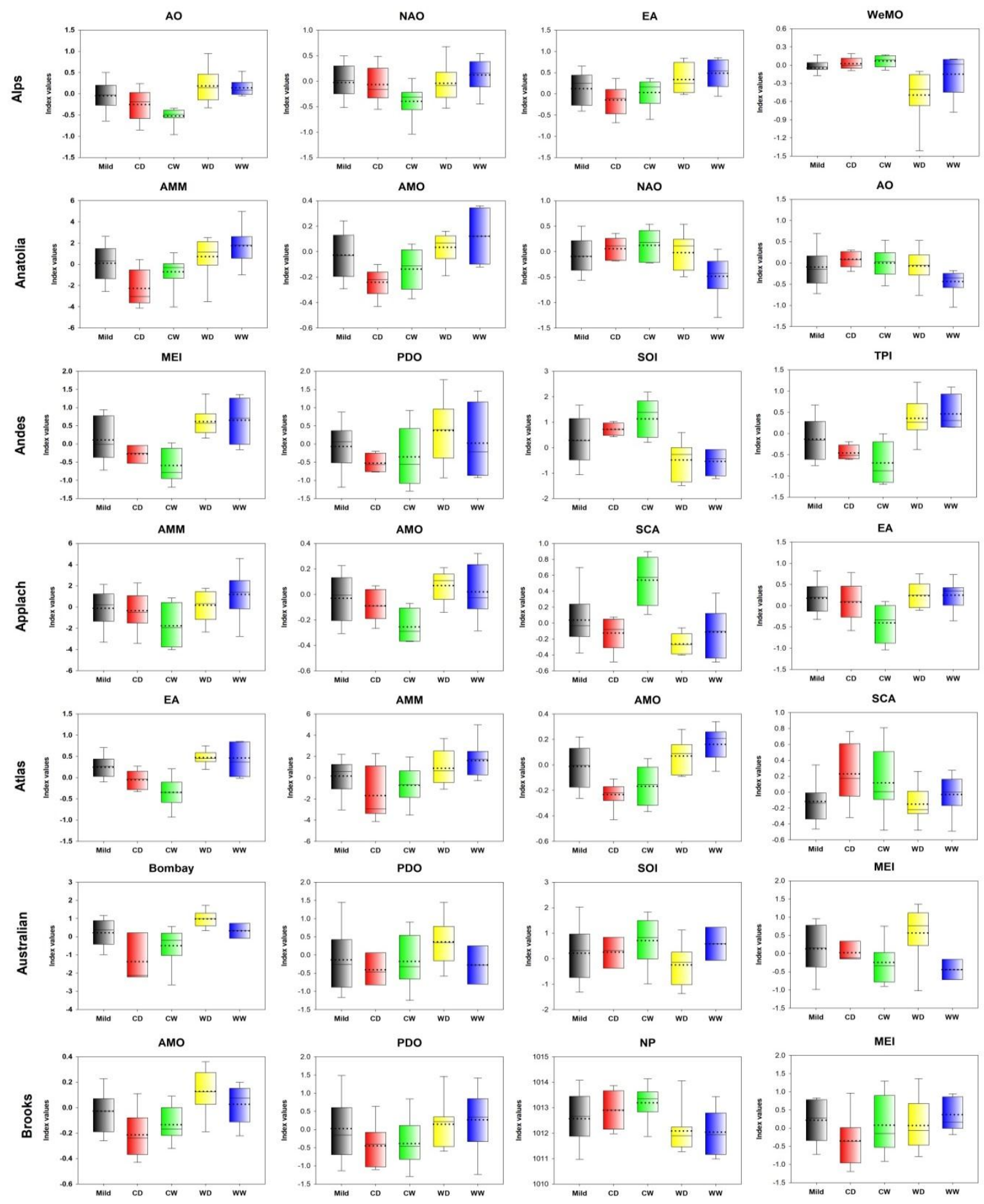

Figure 13: Values of the circulation indices corresponding to each climate mode. Mild mode refers to those modes with average "normal" climatic conditions (i.e. $30^{\text {th }}$ perc $<$ Tmean $<70^{\text {th }}$ perc and $30^{\text {th }}$ perc $<$ Precip $<70^{\text {th }}$ perc). The plotted indices are the most correlated four teleconnections with climate modes in each mountain regime. The central solid line indicates the median, whereas the central dashed line refers to the mean. The whiskers represent the 10 th and the 90 th, while the 25 th and the $75^{\text {th }}$ are plotted as the vertical lines of the bounding boxes. 

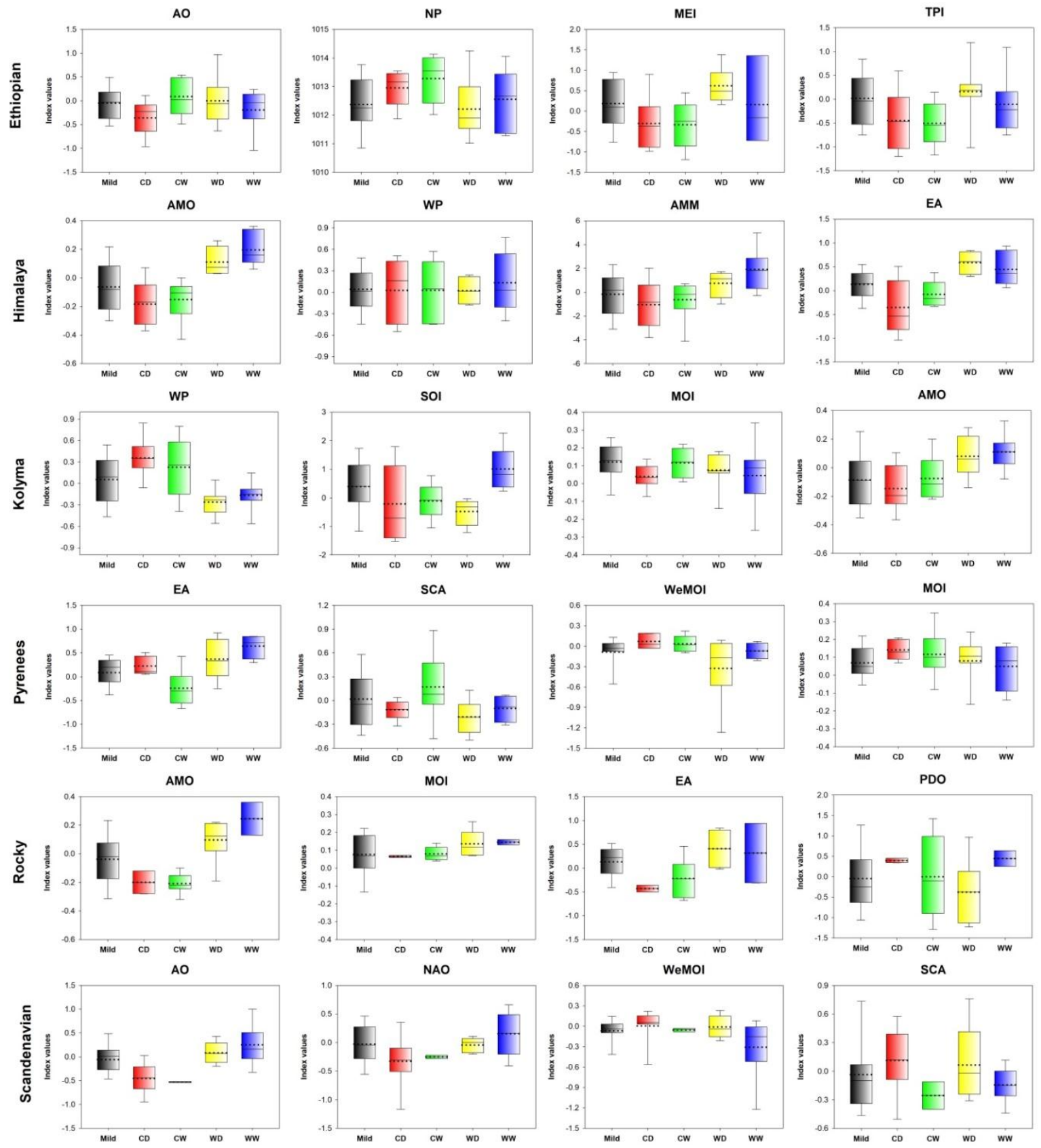

Figure 13: continued. 


\title{
التقييم الهيدرومناخي للأقاليم الجبلية الرئيسة في العالم خلال العقود الخمسة الأخيرة
}

\author{
د. أحمد القناوي ،أ.م.د.حسام اسماعيل
}

الملخص

تهدف هذه الدراسة إلي تقييم التباينات المكانية والزمانية في استجابة الأقاليم الجبلية الرئيسة في العالم للتغيرات المناخية خلال العقود الخمسة الأخيرة، وقد اعتمدت هذه الدراسة علي البيانات المناخية الثهرية المستخلصة من قاعدة

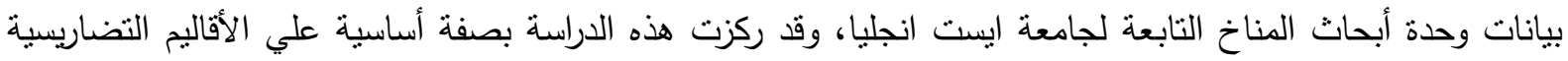

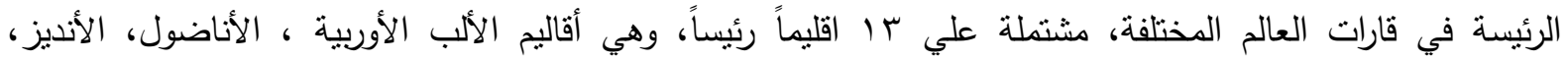

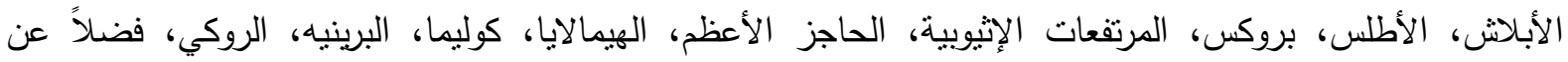
المرتفعات الاسكندينافية، وقد اعتمدت الدراسة علي تقييم التغيرات طويلة الأمد في درجات حرارة الهواء السنوية وكميات

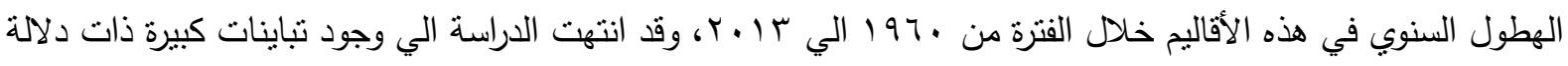
احصائية في تغيرات درجات حرارة الهواء وكميات الهطول بين هذه الأقاليم التضاريسية، فقد شهدت المرتفعات الثمالية في نصف الكرة الثمالي (كالمرتفعات الاسكنيدنافية، ومرتفعات بروكس وكوليما) أعلي معدلات للتغير بين الأقاليم الجبلية في

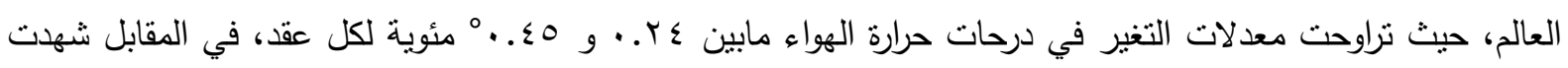

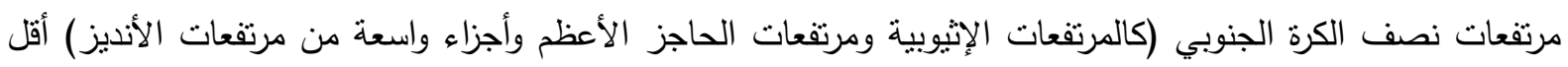

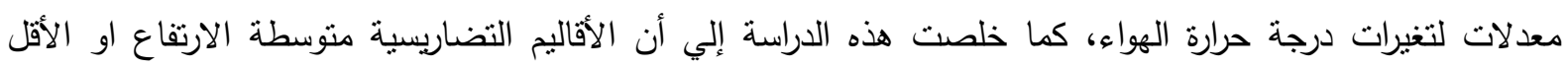

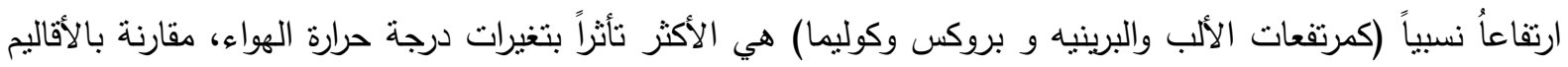

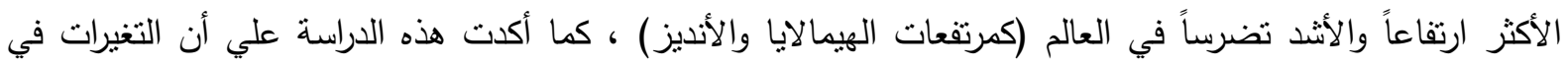
كميات الهطول السنوي أقل تجانساُ مقارنة بتغيرات درجة حرارة الهواء، فقد شهدت مرتفعات الأندات الألب الأوربية والبرينية

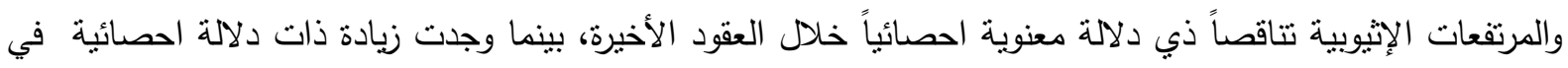

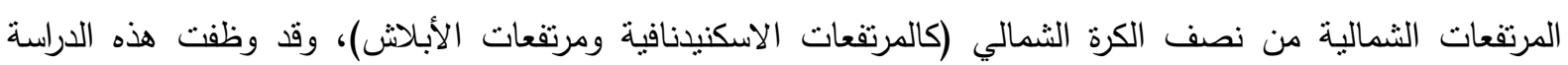
أسلوب التحليل العاملي لاكتثاف الأنماط المتثابهة في التغيرات الزمانية لدرجات حرارة الهواء وكميات الهطول السنوي

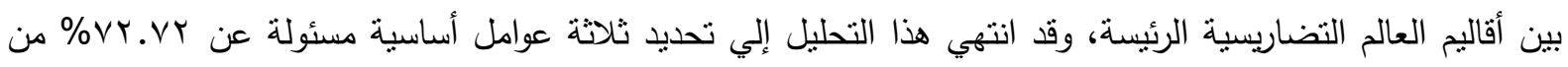

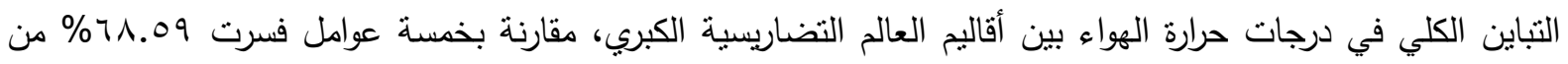
التباين الكلي في كميات الهطول في هذه الأقاليم، كما اعندت هذه الدراسة علي أسلوب المئينات الاحصائية لتحديد أنماط ودرجات الاقتران في تغيرات درجة حرارة الهواء وكميات الهطول في هذه الأقاليه، مع التركيز علي أربعة فئات أساسية

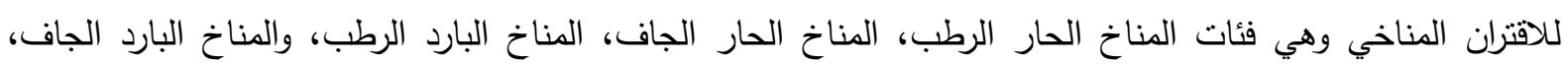

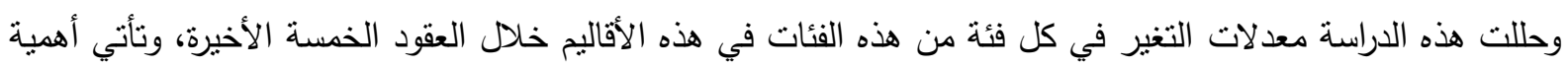
نتائج هذه الدراسة من تقييمها لدور التغيرات المناخية في واحدة من اكثر أقاليم العالم حساسية للتغيرات المناخية، وهي

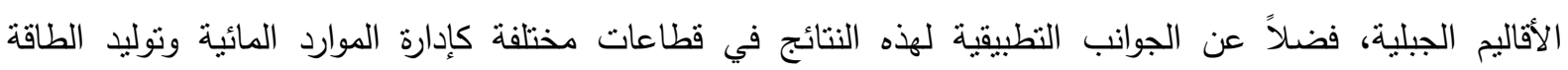
الكهرومائية والتتوع البيولوجي وغيرها، بالإضافة إلي التأثيرات الاقتصادية والاجنماعية وربما السياسية لهذه النتائج في هذه فئه الأقاليم 
الكلمات المفتاحية: الأمطار ، درجة حرارة الهواء، الإقتران المناخي، التباينات الطبوغرافية، الاقاليم التضاريسية الكبري. 